\title{
EL BUEN INMIGRANTE: REGULAR E INTEGRADO
}

\author{
Ángeles SOLANES CORELLA \\ Profesora Titular de Filosofía del Derecho \\ INSTITUT DE DRETS HUMANS \\ UNIVERSITAT DE VALÈNCIA*
}

SUMARIO: I. Introducción. II. Mercado de trabajo y situación administrativa regular: una difícil dicotomía. III. La integración como factor de estabilización de la inmigración. IV. Un viraje en forma de selección y recorte. V. Reflexiones finales.

Resumen: Este artículo tiene por objeto abordar dos de las premisas básicas de la política de extranjería española: el fomento de la inmigración legal y la integración. Con esta finalidad, en primer lugar, se analiza la conexión entre el mercado de trabajo y la situación administrativa regular. En segundo lugar, se cuestiona el papel que desempeñan las actuales políticas de integración como elemento de cohesión social. Por último, se trata de examinar el reciente cambio selectivo en la política de inmigración. Todo ello permitirá valorar las implicaciones y las tensiones entre las mencionadas premisas básicas de la política de extranjería española y su concreción a nivel jurídico.

Palabras Clave: Política de extranjería española, inmigración, mercado de trabajo, integración, igualdad en derechos.

\section{THE GOOD INMIGRANT: REGULAR AND INTEGRATED}

ABSTRACT: This article aims to address two of the basic premises of Spanish immigration policy: the promotion of legal immigration and integration. For this purpose, firstly, it discusses the connection between the labour market and the regular administrative situation. Secondly, it questions the role of current integration policies as an element of social cohesion. Finally, the recent selective change in the immigration policy is examined. This leads to the assessment of the implications and strains between the above basic premises of Spanish immigration policy and its implementation at the legal level.

KEYWORDS: Spanish immigration policy, immigration, labour market, integration, equal rights.

\footnotetext{
* Este artículo ha sido realizado en el marco del proyecto Consolider Ingenio CSD-2008-00007 El tiempo de los derechos, financiado por el Ministerio de Educación; el proyecto Prometeo 2010/099 de la Generalitat Valenciana y el proyecto I+D del Ministerio de Ciencia e Innovación Inmigración, Integración y Políticas públicas: garantías de los derechos y su evaluación, DER 2009-10869.
} 


\section{Introducción}

Entre los fenómenos sociales que han provocado en las dos últimas décadas un mayor impacto de transformación en España, es especialmente significativo el de los flujos migratorios. De hecho el porcentaje de extranjeros en territorio español se sitúa en torno al I2.I\% de la población empadronada (más de 5,7 millones de personas), es decir, en una proporción muy semejante a la de otros países europeos que han sido tradicionalmente receptores de inmigrantes, convirtiéndose en el segundo Estado miembro de la Unión Europea (UE-27), tras Alemania, por número de residentes extranjeros (Moreno y Bruquetas 20II,I3). Es más, hasta el 2006 la inmigración podía considerarse el primer factor de crecimiento de la población, ocho de cada diez nuevos habitantes eran extranjeros (Izquierdo 2006a, I7). Siendo significativo el volumen, también lo es, además, el hecho de que este crecimiento de la inmigración en España se ha producido en un período de tiempo reducido. Así entre 1995 y 2005 España se situó entre los principales receptores de inmigración a nivel mundial, junto a países como, por ejemplo, Estados Unidos (Naciones Unidas A/60/87I 2006, 31).

Sin embargo desde finales de 2007 , como consecuencia de la crisis económica y con ella el aumento del desempleo y el ajuste presupuestario, se ha intensificado un debate acerca de la necesidad y oportunidad tanto de la entrada de nacionales de terceros países, cuanto de la residencia de los que ya se encuentran en España. En este contexto, parece haberse olvidado que el significativo crecimiento español entre I990 y 2007 , es deudor en buena medida de la recepción de mano de obra inmigrante, que claramente permitió la transición de los trabajadores autóctonos hacía empleos con mejores condiciones mientras que los denominados nichos laborales eran ocupados por población extranjera que a su vez también fue ubicándose progresivamente mejor (en relación al mayor período de residencia). Es decir, según los datos de los distintos regímenes de la Seguridad Social de los trabajadores extranjeros, en los últimos años antes de la crisis, se observó un aumentado del peso del Régimen General en detrimento de regímenes laborales especiales (como el agrario y el de empleados de hogar, ambos incluidos, por otra parte, de forma sistemática en los contingentes) cuyas condiciones laborales son peores. De dicha movilidad ascendente, aunque con limitaciones, podían extraerse diversas conclusiones: el ascenso hubiera sido imposible sin las regularizaciones que abrieron el camino a la legalidad; el contexto de fuerte crecimiento económico fue decisivo para que las personas extranjeras consiguieran una cierta promoción en el ámbito laboral; la movilidad de trabajadores extranjeros se esperaba que dejara vacantes en el mercado laboral «por debajo» de los puestos de ascenso, que requerirían de nuevos inmigrantes para ser cubiertas, de forma que podría continuar un flujo migratorio no necesariamente en las dimensiones de la década anterior, pero en todo caso, ligado al desarrollo económico de sectores cruciales, como por ejemplo, la construcción (Pumares, García y Asensio 2006, III-II4 y I96-I99).

La crisis ha modificado completamente el panorama del mercado de trabajo español. La inquietud por la deriva de la difícil situación económica actual, ha supuesto a nivel social que percepciones en contra de la inmigración, que venían siendo anualmente anunciadas por el Centro de Investigaciones Sociológicas al señalar desde 2002 que la inmigración era uno de los problemas que más preocupaba a los españoles, hayan calado especialmente entre la población autóctona más vulnerable. Así, por ejemplo, en buena medida actualmente la inmigración es vista por la población autóctona, especialmente los jóvenes, como un factor del aumento del desempleo y del descenso de los salarios puesto que se cree que los inmigrantes «trabajan por menos dinero». La crisis económica ha acaparado gran parte de la discusión grupal. Los jóvenes al encontrarse en situación de elevada vulnerabilidad al desempleo y al trabajo precario, pese a su elevado nivel de formación, muestran su rechazo a la inmigración (Cea D’Ancona y Valles 20I0, I47).

El discurso político en torno a la movilidad humana, y por ende su traslado al ámbito jurídico-normativo, no ha sido ajeno a esa percepción progresivamente más negativa 
de la inmigración. Teniendo en cuenta además la politización que la cuestión migratoria ha sufrido, al ver en ella los partidos mayoritarios una potencial fuente de votos (Zapata 2003), no es de extrañar que la denominada política de inmigración española, o mejor el conjunto de medidas adoptadas muchas veces de manera improvisada y perentoria para afrontar los flujos migratorios, incida especialmente en su dimensión utilitarista

En este contexto, dos de las recurrentes directrices de la Unión Europea se han convertido en los pilares de nuestra política de inmigración y extranjería: la inmigración legal (por tanto la lucha contra la inmigración irregular en todos los frentes y con especial atención a los mecanismos de control de fronteras) y la integración. En efecto, desde que en I999 con el Tratado de Ámsterdam apareció como objetivo la creación de un espacio de libertad, seguridad y justicia, estableciendo una clara relación entre la libre circulación de personas y el control de los flujos migratorios como forma de garantizar dicho espacio, combatir la clandestinidad y la irregularidad ha sido una constante. A partir de este momento el nexo de unión entre la creación y fortalecimiento de dicho espacio y el control de la inmigración es indisoluble. Tal como consagró el Consejo Europeo de Tampere (I4 y I5 de julio de I999), y como se mantiene hasta nuestros días, los problemas políticos, de derechos humanos y de desarrollo de los países de origen y tránsito, debían abordarse desde una política global de la inmigración. Para ello resulta imprescindible la colaboración de los diferentes Estados miembros, pero no la armonización de sus legislaciones.

En esta línea de respeto al pensamiento estatalista pero, al mismo tiempo, de colaboración en las líneas directrices, las dos premisas fácticas que antes señalábamos se han ido perfilando en las legislaciones nacionales. En el caso español, la transposición de diferentes Directivas europeas, y el respeto a las pautas marcadas por diferentes comunicaciones, tal como veremos, ha derivado en lo que podríamos considerar las dos claves para ser un «buen» inmigrante: la regularidad y la integración. Siendo éstas las dos premisas que se le exigen al inmigrante sine qua non, las últimas reformas legislativas y las diferentes medidas pensadas para el fomento de la integración resultan especialmente relevantes para argumentar, valorar y cuestionar hasta qué punto dichas exigencias son factibles o, en realidad, en la retórica del discurso que dice apostar por la gestión eficaz de la inmigración la igualdad en los derechos sigue siendo una cuestión pendiente.

\section{Mercado de trabajo y situación administrativa regular: una difícil dicotomía}

La sucesión de disposiciones legales en el cuestionable formato de continuo solapamiento con derogaciones parciales, distintos reglamentos, múltiples instrucciones y órdenes de desarrollo, se ha convertido en la técnica legislativa habitual para regular el estatuto jurídico de las personas inmigrantes en España ${ }^{\mathrm{I}}$. Sin embargo, estos cambios legales sumamente discutidos apenas han contribuido a modificar las líneas directrices básicas de la normativa de extranjería española. En efecto, los puntos ineludibles de nuestra política de inmigración siguen siendo los de la LO 4/2000, a pesar de las reformas, en cuanto a la necesidad de fortalecer tres ejes de actuación: el control de los flujos migratorios, la lucha contra las redes de tráfico de personas y contra la inmigración clandestina, y la integración (Cfr. De Lucas 2009 y Santolaya 2009). Sin duda en la configuración del espacio de libertad, seguridad y justicia, ha primado una libertad de movimientos hacia el interior que conlleva el que se refuercen los controles en el acceso al

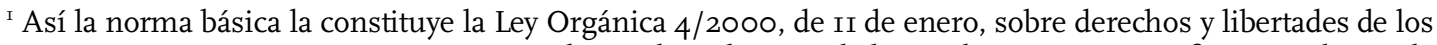
extranjeros en España y su integración social, tras la redacción dada por la Ley Orgánica 8/2000, de 22 de diciembre; por la Ley Orgánica II/2003, de 29 de septiembre, de medidas concretas en materia de seguridad ciudadana, violencia doméstica e integración social de los extranjeros; por la Ley Orgánica I4/2003, de 20 de noviembre y por la Ley Orgánica 2/2009, de in de diciembre (en adelante LODYLE), así como su reglamento de desarrollo aprobado por RD 557/20II, de 20 de abril (BOE de 30 de abril de 20II).
} 
espacio comunitario para de esta manera controlar la inmigración en la Unión (Illamola 2008).

Dichos ejes han sido articulados con distintos énfasis en dimensiones como la económica, la defensiva y la social (De Lucas 2008 y Solanes 2005), siempre con una reincidente atención a la protección del mercado de trabajo. Así no ha resultado nada novedoso que la LO 2/2009 reconociera expresamente que entre sus objetivos está el perfeccionar el sistema de canalización legal y ordenada de los flujos migratorios laborales, reforzando la vinculación de la capacidad de acogida de trabajadores inmigrantes a las necesidades del mercado de trabajo.

Esa teórica voluntad de fomentar una inmigración regular y ordenada en base a las necesidades laborales fue la que justificó el establecimiento del sistema de contingentes o cuotas anuales de entrada en España que ha llegado, con modificaciones, hasta nuestros días. Aunque en su concepción inicial dicha previsión se articuló para que pudieran acogerse a la misma los extranjeros que deseaban venir a España a trabajar, siendo así la vía legal de entrada, la realidad entre I993 y I999 ya demostró que funcionaba como una especie de regularización encubierta. Esta situación resultó a largo plazo insostenible, puesto que, suponía un estímulo indirecto a la inmigración irregular y, sobre todo, impedía el establecimiento de un control legal efectivo (Aja 2006, 25). Por ello el sistema de contingentes fue sistemáticamente sometido a control y revisión hasta dejar paso a la actual gestión colectiva de contrataciones en origen.

En general, el tránsito desde la LO 4/200o hasta la última de sus modificaciones ha estado marcado por previsiones legales de interpretación restrictiva, hasta tal punto que el Estado español fue llamado al orden por el Tribunal de Justicia de la Unión Europea, en relación al tratamiento jurídico dispensado a los extranjeros en situación administrativa irregular. Así la vulneración del principio de proporcionalidad dio lugar a que el Tribunal de Justicia alertara de que la normativa europea sobre expulsión de irregulares había sido mal interpretada en el ordenamiento jurídico español${ }^{2}$. En realidad no debía entenderse que dicha normativa obliga a las expulsiones, como decía la traducción española, sino que se permite a los Estados miembros ejecutarlas o sustituirlas por multas. Como recuerda el mencionado Tribunal debe interpretarse que cuando un nacional de un tercer país se encuentra en situación irregular en el territorio de un Estado miembro, porque no cumple o ha dejado de cumplir los requisitos relativos a la duración de la estancia aplicables en él, dicho Estado miembro no está obligado a adoptar contra él una resolución de expulsión.

Con el mencionado mecanismo de gestión colectiva de contrataciones en origen introducido por la LO 2/2009 y con el catálogo de ocupaciones de difícil cobertura que lo sigue completando, la dialéctica mercado de trabajo-regularidad ha permanecido inalterada. Tan sólo se mantiene la consabida excepción de la reagrupación a la que finalmente se ha incorporado la tradicional reivindicación relativa a que los agrupados (sólo cónyuge e hijos, según las disposiciones normativas) podrán acceder al mercado de trabajo sin necesidad de ulterior autorización administrativa.

En un contexto marcado por las escasas propuestas de inclusión de ocupaciones recibidas de las Comunidades Autónomas, junto con la información suministrada por el

\footnotetext{
2 2009/C 297/II. Asuntos acumulados C-261/08 y C-348/08: Sentencia del Tribunal de Justicia (Sala Tercera) de 22 de octubre de 2009 (petición de decisión prejudicial planteada por el Tribunal Superior de Justicia de Murcia) - María Julia Zurita García (asunto C-26r/o8), Aurelio Choque Cabrera (asunto C348/o8)/Delegado del Gobierno en la Región de Murcia, Visados, asilo e inmigración - Medidas sobre el cruce de las fronteras exteriores - Artículo 62 CE, nos I y 2, letra a) - Convenio de aplicación del Acuerdo de Schengen - Artículos 6 ter y 23 - Reglamento (CE) n ${ }_{5}$ 62/2006 - Artículos 5, II y I3 - Presunción sobre la duración de la estancia - Nacionales de terceros países en situación irregular en el territorio de un Estado miembro Normativa nacional que permite imponer, según las circunstancias, bien una multa o bien la expulsión. DOUE 5 de diciembre de 2009 .
} 
Servicio Público de Empleo Estatal sobre la situación nacional de empleo, no resulta extraño que en la concreción de la gestión colectiva de las contrataciones en origen durante los años 20I0 y 20II, el número de contrataciones de carácter estable que se han realizado hayan estado limitadas a un conjunto muy reducido de ocupaciones ${ }^{3}$. Esta restricción en el mecanismo por excelencia de ordenación de flujos migratorios y de la garantía de la cobertura de las ofertas de empleo no cubiertas por el mercado de trabajo nacional, supone en la práctica una rigidez en la posibilidad de entrada y permanencia en situación administrativa regular que se corrobora con las restricciones en el catálogo de ocupaciones de difícil cobertura.

Además, la articulación formal de las autorizaciones iniciales de trabajo se ha complicado con la LO 2/2009, al transferir su gestión a las Comunidades Autónomas. Siendo imposible abordar una cuestión de semejante envergadura en este estudio, conviene ahora apuntar la atribución de competencias a dichas Comunidades sin que ello suponga una pérdida del control de las entradas por cuestiones laborales a nivel estatal. Así, por lo que respecta a la transferencia de competencias es fundamental la sentencia dictada por el Tribunal Constitucional, el 28 de junio de 20ıо, que resuelve uno de los siete recursos de inconstitucionalidad interpuestos contra determinados preceptos de la Ley Orgánica 6/2006, de reforma del Estatuto de Autonomía de Cataluña (EAC). En lo relativo a la inmigración es vital el fundamento jurídico número 83 en el que se afirma que «es evidente que la competencia en materia de entrada y residencia de extranjeros se inscribe en el ámbito de la inmigración y la extranjería, terreno en el que, como alegan los recurrentes, sólo cabe la competencia exclusiva del Estado. Ahora bien, el propio art. I38.2 EAC así lo reconoce al condicionar el ejercicio de la competencia ejecutiva autonómica a la coordinación con el Estado, quien, como titular de la competencia preferente entre las que concurren a la regulación del régimen jurídico de los extranjeros en tanto que inmigrantes, no puede hacer entera abstracción, sin embargo, de competencias sectoriales atribuidas a las Comunidades Autónomas, como es el caso, en lo que importa ahora, de la competencia ejecutiva en materia de legislación laboral»... «es a la legislación estatal a la que corresponde libremente determinar los concretos términos, formas y condiciones de la participación de la Comunidad Autónoma a la que se refiere el precepto, debiendo en todo caso quedar a salvo la titularidad de las competencias estatales eventualmente implicadas y la perfecta libertad que en su ejercicio corresponde a los organismos e instituciones del Estado»... «el art. I3 8 EAC ha de interpretarse en el sentido de que la referencia a la 'inmigración' no se corresponde con esta materia constitucional, competencia exclusiva del Estado (art. I49.I.2 $\mathrm{CE}$ ), sino con otras materias sobre las que puede asumir competencias la Comunidad Autónoma». Desde esta interpretación es posible afirmar que esta decisión no tendrá incidencia sobre las reformas adoptadas en los últimos años para desarrollar el mandato estatutario, en especial las introducidas por los RD II62/2009 y RD I463/2009; y por el RD 206/20Io, de 26 de febrero, sobre traspaso de funciones y servicios a la Generalitat de Cataluña en materia de Función Pública Inspectora de la Inspección de Trabajo y Seguridad Social (García Juan 2010).

Por otra parte, las restricciones al mercado nacional de empleo se han extendido incluso al régimen comunitario. El Tratado de Adhesión de Rumanía a la Unión Europea (I de enero de 2007), contemplaba (en el anexo VII del Acta relativa a las condiciones de adhesión y a las adaptaciones de los Tratados en los que se fundamenta la Unión Europea), la posibilidad de un período transitorio de hasta siete años durante el cual los Estados miembros podrían establecer medidas para regular el acceso de los nacionales rumanos al mercado de trabajo. En el caso español así se hizo por Acuerdo del Consejo de Ministros de

${ }^{3} \mathrm{Si}$ se consulta, por ejemplo, la Orden TIN/3364/2010, de 28 de diciembre, por la que se regula la gestión colectiva de contrataciones en origen para $20 \mathrm{II}$ (BOE de 30 de diciembre de 2010 ), las ofertas son muy limitadas y además no se contempla la concesión de visados para búsqueda de empleo, dirigidos a hijos y nietos de español de origen o limitados a determinadas ocupaciones en un ámbito territorial concreto. Es llamativo que la totalidad de las ofertas hagan referencia a distintas especialidades médicas como pediatría, urología o cardiología. 
22 de diciembre de 2006 , concretando una duración de dos años, si bien al final del primer año, se acordó que se evaluaría los efectos de la aplicación de dicho período transitorio para acordar su continuidad o no. En el Acuerdo del Consejo de Ministros de 28 de diciembre de 2007 se dispuso que el período transitorio continuara durante 2008 y que, una vez finalizado este año, el acervo comunitario sobre libre circulación de trabajadores se aplicara íntegramente en España a los trabajadores rumanos. Sin embargo, el mencionado anexo VII del Acta relativa a las condiciones de adhesión incluye la posibilidad de que los Estados miembros reactiven el período transitorio cuando sufran perturbaciones en su mercado de trabajo que puedan poner en grave peligro el índice de empleo y suspendan, por tanto, la aplicación de los artículos i a 6 del Reglamento (CEE) n. ${ }^{\circ}$ I6I2/68, relativos a la libre circulación de trabajadores. Eso es precisamente lo que se ha hecho con los trabajadores de Rumanía. El Consejo de Ministros, en su reunión del día 22 de julio de 20 II y a propuesta de los Ministros de Trabajo e Inmigración, de Asuntos Exteriores y de Cooperación y del Interior, adoptó un Acuerdo por el que se establece la reactivación del periodo transitorio en relación con la libre circulación para los mismos hasta finales de 20I2. En esta fecha el Gobierno evaluará los efectos de ese período transitorio y en función de las conclusiones a que se llegue, acordará la continuidad del mismo o lo dará por finalizado aplicando plenamente el acervo comunitario sobre libre circulación de trabajadores a los nacionales rumanos ${ }^{4}$.

En este contexto marcado por un mercado de trabajo deficitario, volviendo al régimen de extranjería propiamente dicho, la dificultad en la permanencia dentro de la situación administrativa de regularidad, ha sido asimismo el germen de los denominados programas de retorno para los nacionales de terceros Estados sometidos a la LODYLE y sus normas de desarrollo. En mi opinión, estos programas han sido pensados para contrarrestar la primera de las fuerzas push-pull, en la clásica terminología de Ravenstein (I885 y i889) que sorprendentemente permanece en muchos aspectos inalterada en relación al predominio otorgado al factor económico en las migraciones (Arango I985, I4).

Ciertamente si nos centramos en los programas de retorno voluntario asistido (dejando de lado el denominado retorno forzoso, eufemismo consagrado por la Directiva 2008/II5/CE para referirse a supuestos de expulsión), las distintas alternativas articuladas fueron pensadas para descomprimir un mercado de trabajo que ya no demandaba determinada mano de obra, aunque los resultados no hayan sido los esperados ${ }^{5}$. Así el retorno asistido en España se ha articulado en tres modalidades: el llamado retorno por causas humanitarias (destinado a personas en situación de vulnerabilidad social); el retorno asistido con reintegración (que implica la voluntad del retornado de emprender un proyecto productivo en su lugar de origen); y el Plan de Retorno Voluntario, elaborado por el gobierno ante el enfriamiento de la economía (que pretende facilitar la búsqueda de oportunidades en otros países a los migrantes facilitándoles el cobro anticipado de la prestación por desempleo que hubieran generado en España $\left.{ }^{6}\right)$. A pesar de las indiscutibles

\footnotetext{
${ }^{4}$ Vid. Orden PRE/2072/20II, de 22 de julio, por la que se publica el Acuerdo de Consejo de Ministros por el que se establece la reactivación del periodo transitorio en relación con la libre circulación de los trabajadores de Rumanía. BOE de 23 de julio de 201 I.

5 Como mantiene Pajares (20I0, II8-I24) el retorno de inmigrantes, aun cuando no fue una opción importante frente a la crisis casi compensó en 2009 el número de entradas, y los datos de 2010 confirmaron esta tendencia.

${ }^{6}$ Entre los requisitos que el extranjero debe cumplir para poder cobrar el pago acumulado y anticipado de la prestación contributiva por desempleo figuran: ser nacional de un país que tenga Convenio bilateral con España en materia de Seguridad Social y tener residencia legal en España; estar desempleado e inscrito como demandante de empleo; tener reconocido el derecho a la prestación por desempleo de nivel contributivo, sin compatibilizarlo con un trabajo a tiempo parcial; asumir el compromiso de retornar a su país de origen en el plazo máximo de 30 días naturales contando a partir de la fecha del primer pago en España y el de no retornar a España en el plazo de tres años; y no estar incurso en los supuestos de prohibición de salida del territorio nacional previstos en la legislación de extranjería. Por tanto, en cumplimiento de la primera exigencia, sólo pueden acogerse a esta previsión los nacionales de Estados con los que España tiene convenio en materia de Seguridad Social que son: Andorra, Argentina, Australia, Bolivia, Brasil, Canadá, Chile, Colombia, Ecuador,
} 
ventajas del retorno voluntario, frente al forzoso, en cuanto a su impacto en el inmigrante a todos los niveles, las cifras de retornados han sido muy bajas desde que comenzaran a articularse estos programas en España.

Hay que tomar en consideración determinadas variables para entender hasta qué punto la visión del legislador y su concreción en programas pensados para fomentar la regularidad, dista de la percepción de la realidad que puede tener el inmigrante. En este sentido, resulta verosímil el pensar que los incentivos diseñados por los mencionados programas han resultado insuficientes para motivar el comportamiento de sus destinatarios, al tiempo que aún existiendo una crisis económica en España que azota al mercado de trabajo (con altos índices de desempleo y la vuelta de la población autóctona a trabajos que en décadas anteriores fueron considerados como nichos laborales e introducidos en los contingentes ofertados a nacionales de terceros Estados) la situación española es comparativamente mejor a la de países emisores de emigrantes. Asimismo se han reconocido importantes obstáculos en la implantación de este tipo de programas como la falta de recursos materiales y humanos necesarios para su realización y el desconocimiento de información tanto acerca de las personas retornables como sobre las circunstancias y proceso del retorno voluntario asistido (EMN 2009, 5I-52).

Que el mercado laboral expela de la regularidad a una cantidad significativa de personas sometidas al estatuto legal de extranjería, no es óbice para que éstas, por factores no vinculados a la regularidad que otorga la autorización de residencia y trabajo (como las redes sociales ya establecidas y la posibilidad de conseguir ingresos aunque sea en el ámbito de la economía sumergida) decidan permanecer en España. Es más, la incertidumbre entorno al proceso de reintegración y la sostenibilidad del retorno voluntario asistido, hace que surjan dudas razonables en la motivación para acogerse a este tipo de programas.

El ajuste a través del retorno voluntario no ha sido, por tanto, el inicialmente esperado, ya que tan sólo se ha dado de manera limitada, lo que podría suponer un incremento de la economía sumergida. Como destaca la EMN (20Iob, 88) nos encontramos con un volumen muy importante de mano de obra disponible, en parte desempleada, procedente de la inmigración y ya residente en el país. A ello habrá que sumar la entrada de inmigrantes por vía de la reagrupación familiar (La Spina 20II). Por tanto, «nos vamos a encontrar durante un cierto tiempo no con escasez de mano de obra, sino con excedente de mano de obra ('labour surplus'), que implicará a trabajadores inmigrantes, frente al que habrá que tomar medidas».

A esas políticas públicas potenciadoras del retorno voluntario, hay que añadir el hecho de que la «libre» decisión de acogerse a un programa puede responder también simplemente a la salida de personas de nuestro país hacia el suyo de origen o hacia terceros Estados en busca de mejores oportunidades, o una cuestión más compleja como sería su «invisibilidad jurídica» por no cumplir los requisitos legales para residir y/o trabajar en España (Rojo 20Io, 66).

Junto a las dificultades para el acceso y permanencia en España en situación administrativa regular, otro determinante mecanismo de la política de inmigración se ha visto vinculado recientemente a la tiranía del mercado de trabajo. Me refiero a una de las formas de acceso a una autorización de residencia o trabajo a través de las previsiones del Título V, del mencionado RD 557/20II, relativo a la residencia por circunstancias excepcionales, en concreto el denominado arraigo social.

Conviene comenzar señalando que el reglamento de 20II ha mantenido la configuración del arraigo, con dos importantes matizaciones: la reducción del periodo de 
relación laboral a acreditar en el denominado arraigo laboral; y la introducción de la figura del arraigo familiar para progenitores de menores españoles. Asimismo el reglamento de 20 II ha introducido novedades importantes, por ejemplo, en relación a la figura de la víctima de violencia de género, respecto a la cual se establece la posibilidad de acceder a una autorización de residencia y trabajo provisional, y en caso de sentencia condenatoria o resolución judicial de la que se deduzca que la mujer ha sido víctima de violencia de género la posibilidad de acceder a una autorización de cinco años; o la incorporación de una situación especial para la figura de la víctima de trata de seres humanos, tanto en su vertiente de trata con fines de explotación sexual como en su vertiente de fines de explotación laboral.

De las distintas modalidades de residencia por circunstancias excepcionales, el arraigo social ha sido una de las más utilizadas como procedimiento ordinario de acceso a la regularidad. Entre las concreciones que ha introducido el RD 557/20II en la gestión administrativa de este procedimiento destaca su vinculación a la situación nacional de empleo. Así el artículo i24.4 del reglamento señala que por Orden del titular del Ministerio de la Presidencia, a propuesta de los titulares de los Ministerios del Interior y de Trabajo e Inmigración, y previo informe de la Comisión Laboral Tripartita de Inmigración, se podrá determinar la aplicación de la situación nacional de empleo a las solicitudes de autorización de residencia temporal por razones de arraigo social. Esta previsión, en su articulación práctica, supone cerrar la vía más flexible (dentro de la rigidez general) de regularización ordinaria. La combinación entre la reducción cuantitativa en las entradas legales que se ofertan, como veíamos anteriormente, y la limitación en el acceso a autorizaciones de residencia y trabajo para quienes se encuentren en situación irregular no es, en mi opinión, la mejor forma de favorecer esa gestión de la inmigración para fomentar los flujos en situación administrativa regular.

Cuestionar la sumisión a la situación nacional de empleo en el caso del arraigo social no supone defender una excepción al requisito legal de acreditar un contrato. Este reproche no es tanto a la exigencia del artículo I24.2 b) del RD 557/20II al requerir que en este tipo de arraigo el extranjero cuente con un contrato de trabajo firmado por el trabajador y el empresario en el momento de la solicitud para un periodo que no sea inferior a un año, cuanto al hecho de que pueda acreditarlo (cuando efectivamente sea ésta su voluntad y la de su empresario) sin que le sea de aplicación la situación nacional de empleo. Ciertamente las perturbaciones del mercado de trabajo, como en el caso anteriormente mencionado de los nacionales rumanos, y las preocupantes cifras de desempleo, son ahora, más que nunca, un argumento de control y restricción de los flujos migratorios en una determinante imposición de la economía a los derechos.

Otra de las dificultades en el acceso a la situación administrativa irregular por la vía de las circunstancias excepcionales, y en concreto en los supuestos de arraigo no sólo social sino también laboral, tiene que ver con la acreditación de la permanencia continuada en España, de dos años como mínimo en el arraigo laboral y de tres años en el arraigo social. Me refiero a la acreditación de dicha permanencia continuada a través de la inscripción padronal. Tal como ya había ocurrido en las reformas legales anteriores, la LO 2/2009 y el RD 557/20II, han endurecido el régimen de infracciones y sanciones en la parte vinculada a la inscripción padronal.

Así el artículo 53.I c) considera infracción grave: incurrir en ocultación dolosa o falsedad grave en el cumplimiento de la obligación de poner en conocimiento de las autoridades competentes los cambios que afecten a nacionalidad, estado civil o domicilio; y la falsedad en la declaración de los datos obligatorios para cumplimentar el alta en el padrón municipal a los efectos previstos en esta Ley, siempre que tales hechos no constituyan delito. Si cualquier autoridad tuviera conocimiento de una posible infracción por esta causa, lo pondrá en conocimiento de las autoridades competentes con el fin de que pueda instruirse el oportuno expediente sancionador. Asimismo, el artículo $53.2 \mathrm{~d}$ ) innova una 
infracción grave más en relación al registro municipal: el consentir la inscripción de un extranjero en el padrón por parte del titular habilitado de una vivienda, cuando dicha vivienda no constituya el domicilio real del extranjero. Se incurre en tantas infracciones como personas indebidamente se inscriban en dicha vivienda. Previsiones de este tipo suponen en su dimensión material una dificultad más para que el extranjero pueda acreditar su empadronamiento y con ello la permanencia en España que el arraigo exige para regularizar su situación (Solanes 2010 a).

A todas las dificultades señaladas para acceder a la situación administrativa regular en España y permanecer dentro de ella, hay que añadir de forma transversal las discriminaciones de que son objeto los inmigrantes en el mercado de trabajo a pesar de ser éste la llave de su estatuto jurídico y, en buena medida, de su integración como veremos más adelante. Así, por ejemplo, el Consejo para la promoción de la Igualdad de Trato y no discriminación de las personas por el origen racial o étnico, en su estudio sobre comportamientos discriminatorios en España (marzo 20II) evidencia que las personas de origen subsahariano son el grupo estudiado que manifiesta ser discriminado en mayor proporción y en mayor número de situaciones. Por otra parte, los ámbitos en los que la discriminación étnica o racial se presenta con más frecuencia para todos los colectivos, son la vivienda, el empleo y el relativo a la relación con la policía. En la misma línea se pronuncia la Agencia Europea de Derechos Fundamentales, en el informe anual de 20ı0, al señalar que el empleo es donde mayor discriminación social se da en España y ,sin embargo, la legislación antidiscriminación no es bien conocida ni por el público ni por los profesionales del Derecho.

Por ello, la Comisión Europea contra el Racismo y la xenofobia (ECRI 20II, 25) en su informe de febrero 20II, recomienda a las autoridades españolas que doblen los esfuerzos para combatir la discriminación en el ámbito laboral, en concreto respecto al colectivo de musulmanes del Norte de África por entender que ha sido el más afectado por la discriminación en el mercado de trabajo (aduciendo razones como, por ejemplo, que el respeto del mes del Ramadán reduce su capacidad de trabajo). Aún admitiendo que la mayor tasa de desempleo de los inmigrantes no es atribuible a cuestiones vinculadas con la discriminación racial, sino al colapso de nuestra economía en concreto en sectores que tradicionalmente habían demandado mano de obra extranjera, como por ejemplo la construcción, no puede obviarse que, pese a la recesión, los inmigrantes siguen llegando a España y la discriminación continua. Por ello la ECRI también recomienda a las autoridades españolas que se aseguren de que la legislación se utiliza para combatir la discriminación racial en el empleo.

\section{La integración como factor de estabilización de la inmigración}

La cuestión de la integración como prioridad esencial al tratar el fenómeno migratorio, requeriría un análisis transversal que supera las posibilidades de este trabajo. Sin embargo, si la afrontamos como segundo eje de la política de inmigración española, desde los múltiples aspectos a considerar para articular una política de integración de y con los inmigrantes (Cachón 2008), uno especialmente relevante lo constituye, a mi juicio, el estatuto jurídico. Ciertamente las condiciones jurídicas que normativamente se atribuyen a los extranjeros sometidos a la LODYLE en virtud del tipo de autorización de que disponen, supone un factor de (des o) estabilización.

En esta ocasión, en lugar de ocuparme del contenido de dicho estatuto jurídico, analizaré lo que la integración desde su dimensión legal supone, tomando como punto de partida la consideración de que ésta sólo es posible desde la igualdad de libertades y deberes, puesto que no puede haber integración sin derechos, y no a la inversa (De Lucas y Solanes 2009). 
Aunque la LO 4/2000 ya hacía una referencia en su título a la cuestión de la integración en su dimensión social, hasta la última de las leyes orgánicas de reforma, la LO 2/2009, no se había dedicado una parte del articulado a concretar dicha cuestión, tal como veremos más adelante. Con la LODYLE se han ido trazando escalones diferentes de derechos atendiendo a la regularidad de la situación administrativa pero también al empadronamiento, éstos son los dos referentes para que los extranjeros puedan ejercer sus derechos en España.

En cualquier caso, la superación de la tradicional exclusión de la que ha sido objeto la persona inmigrante sólo puede romperse si se comienza por negar la mayor de las premisas, afirmando que es más que cuestionable el hecho de que todo extranjero procedente de otra cultura deba ser visto como un enemigo, del mismo modo que también lo es que los países que acogen inmigrantes tengan una cultura homogénea y consolidada a la que la persona inmigrante pueda «apuntarse» (¿asimilarse?) como un todo (De Lucas 2003, 52 y Castles 2006).

El aumento paulatino de las personas inmigradas en territorio español requiere la acomodación, inserción o normalización en múltiples ámbitos, entre ellos el jurídicoadministrativo y el social, cuyas premisas no siempre son claras. Es necesario especificar las exigencias del proceso integrador, estableciendo propuestas concretas en torno a lo que podríamos considerar como los «indicadores sociales de la gestión de la convivencia plural en la vida cotidiana» (De Lucas 2006, I3), que se traducen en derechos tales como la sanidad, la educación, la vivienda o el trabajo (Añón 2010).

No basta, con preguntar a los inmigrantes si se sienten o no adaptados a la cultura o costumbres del país de acogida. Desde mi punto de vista no es relevante, per se, que por ejemplo en un estudio realizado sobre la comunidad musulmana en España se afirme que el $83 \%$ de los encuestados se considera adaptado a la vida y a las costumbres de su lugar de residencia en España, mientras que el $74 \%$ dice que en nuestro país se acoge bien a los inmigrantes, o el $67 \%$ declara sentirse claramente a gusto en territorio español. Ni lo es tampoco el hecho de que sólo el ıo\% de los inmigrantes musulmanes entrevistados afirme relacionarse exclusivamente con personas de su misma nacionalidad, y el $15 \%$ mantenga que lo hace exclusivamente con personas de su misma religión. Que el análisis demuestre también, que entre los entrevistados se observa un dominio razonable del español, y entre quienes residen en el litoral mediterráneo, un tercio dice poder manejarse en catalán o valenciano, no es en mi opinión concluyente ${ }^{7}$. Éstos no son indicadores suficientes de integración, es más podría incluso servir para avalar un proceso encubierto de asimilación progresiva si no va unido a un estatuto jurídico garantista que hace no solo que se «sientan» iguales sino que efectivamente sean iguales sujetos de derechos.

Es cierto que la integración aborda temas sensibles como la diversidad cultural y religiosa, que abren y colocan en un primer lugar del debate social cuestiones candentes y muy sensibles como la utilización del velo integral (burka), del pañuelo islámico o la educación religiosa en el espacio público. Es en este contexto donde se ubican las tradicionales cuestiones que generan controversias en las sociedades plurales, incluso a nivel intraestatal con los derechos lingüísticos por ejemplo, que necesariamente han de ser afrontadas si se quiere integrar y no asimilar (Cfr. Cachón 20II). Precisamente por eso el papel del Derecho es fundamental en el establecimiento de los límites de aquello que es aceptable, permitido, obligado o prohibido, pero también en la garantía de igualdad ante la ley de todos los administrados.

\footnotetext{
7 Éstas son algunas de las conclusiones del estudio sobre la Comunidad Inmigrante Musulmana 20Io, realizado por Metroscopia por quinto año consecutivo. Plan Nacional para la Alianza de Civilizaciones y Metroscopia Estudios Sociales y de Opinión, La Comunidad Musulmana de origen inmigrante en España, Gobierno de España, Ministerio del Interior, Ministerio de Justicia y Ministerio de Trabajo e Inmigración, febrero 20II.
} 
Se trata de insistir en la idea de que la integración no ha de ser estrictamente en clave cultural, si no más bien social y especialmente jurídico-política en clave de pertenencia. Es aquí donde entra en juego la noción de ciudadanía que no supone sólo un mera pertenencia a la organización que es el Estado, sino que además establece el estatuto jurídico, en cuanto a su contenido, fijando los derechos y deberes de los ciudadanos. Entre ellos, es necesario incluir los derechos democráticos de los que los sujetos pueden valerse para, de forma reflexiva, cambiar su situación, posición, o condición jurídica material. Si a determinados individuos se les niegan esos derechos, se limita su capacidad de asegurarse un trato igual y de influir sobre la toma de decisiones, cerrando así el círculo de la exclusión (Habermas 2000, 626). El estatuto jurídico pleno es el punto de partida de la integración jurídica, el que la hace posible.

Los derechos y deberes comunes compartidos por el conjunto de personas en el seno del Estado de Derecho apelando al pacto social en la más pura concepción contractualista hacen innecesario, (incluso sumamente discutible si se alude también a las disposiciones internacionales y a la imposibilidad de hacer algunas distinciones en base a ellas), la articulación de obligaciones jurídicas específicas para determinados colectivos más allá de las ya estipuladas en el ordenamiento jurídico común. Los límites en el Estado de Derecho son coincidentes: el respeto a la Constitución y a la ley, tanto para los nacionales, los ciudadanos, los comunitarios o los inmigrantes, porque son (han de ser) compartidos por el conjunto de los administrados, de lo contrario se les está exigiendo a determinadas personas que ofrezcan un plus que no se les requiere al resto (De Lucas 2006, 37).

Por otra parte no puede obviarse que el fenómeno migratorio va unido a la propia esencia de la integración. Si intentamos disociar los términos de inmigración e integración, ya no hablamos propiamente de la primera en una pretendida concepción teórica que la articula desde una dimensión económica, laboral, pero legal. Ya no nos referimos a mano de obra «reclamada» por un mercado formal de trabajo al alza o en recesión pero que parece seguir necesitando al menos personal altamente cualificado que también se verá afectado por las medidas de integración, sino de otras realidades paralelas a los flujos migratorios (Cachón 2009).

Ésta es la cuestión, cómo compatibilizar esa pretensión de integración, ese proceso irrenunciable en la idea de inmigración, con una realidad en la que el estatuto jurídico es desigual y la inmigración irregular está alcanzando una considerable dimensión que repercute directamente sobre la esfera democrática española y sobre los inmigrantes que, como sujetos más débiles, se han visto especialmente afectados por la crisis económica (Izquierdo 2008). En este contexto potenciar la ascensión del proceso de integración a un primer plano en el discurso político, y por ende normativo, exige, deconstruir las actuales formulas legales generadoras de una exclusión estratificada, que reconoce diversos niveles de derechos a los inmigrantes, para dejar paso a un estatuto pleno de derechos para los extranjeros que consolide y refuerce nuestra democracia al acercar la sociedad civil a la jurídica (Mezzadra 2009, 97-100).

Esta propuesta no sólo es compatible con los principios constitucionales, sino incluso más acorde, desde mi punto de vista, que el actual puesto que el marco constitucional es lo suficientemente amplio para facilitar una gestión de la diversidad, sin que en todo caso sean descartables algunas puntuales mejoras. Para evidenciarlo, en este artículo, me detendré, en primer lugar, en la novedosa referencia de la última reforma legal a la integración en la política de inmigración española para ver el encaje que se le pretende dar en el futuro y su coordinación con otras novedades legislativas. Con ello pretendo insistir en que la devaluación de los derechos fundamentales de los inmigrantes, no es más que una reducción en la calidad de nuestras democracias, una reformulación a la baja del Estado de Derecho que ha de ser cuestionada y criticada si se quiere que la integración sea posible. 
En esta línea, es positivo destacar que, por primera vez en la legislación española la LO 2/2009 incorpora un artículo dedicado a la integración de los inmigrantes y se especifica que ésta será un principio fundamental en la articulación de la política inmigratoria española teniendo en cuenta que el acervo de la Unión Europea en materia de inmigración y protección internacional apuesta por lograr un marco de convivencia de identidades y culturas. Así el artículo 2 bis recuerda, en su apartado segundo, que todas las Administraciones Públicas ejercerán sus competencias vinculadas con la inmigración en el respeto a principios como la coordinación con las políticas definidas por la Unión Europea; la ordenación de los flujos migratorios laborales, de acuerdo con las necesidades de la situación nacional del empleo; y la integración social de los inmigrantes mediante políticas transversales dirigidas a toda la ciudadanía.

El artículo 2 ter se ocupa específicamente de la integración de los inmigrantes estableciendo dos puntos de partida imprescindibles:

I. Los poderes públicos promoverán la plena integración de los extranjeros en la sociedad española, en un marco de convivencia de identidades y culturas diversas sin más límite que el respeto a la Constitución y la ley.

2. Las Administraciones Públicas incorporarán el objetivo de la integración entre inmigrantes y sociedad receptora, con carácter transversal a todas las políticas y servicios públicos, promoviendo la participación económica, social, cultural y política de las personas inmigrantes, en los términos previstos en la Constitución, en los Estatutos de Autonomía y en las demás leyes, en condiciones de igualdad de trato.

Es cierto que esta primera referencia expresa al principio de integración en la legislación española de extranjería puede resultar criticable. Ciertamente no se nos proporciona un concepto de integración preciso, y las referencias que se dan para concretar las claves que permitan comprender cuál es la concepción de integración que se propone, permiten avalar tanto una concepción unilateral de la integración que corresponde exclusivamente al inmigrante, cuanto la integración como proceso bidireccional, integral y transversal, en la línea tradicionalmente propuesta desde la Unión Europea.

Con todo, lo reseñable de estas dos afirmaciones es que suponen, en mi opinión, la negación de la existencia del denominado «contrato de integración» para los inmigrantes (exclusivo y excluyente) como obligación jurídica en España, puesto que, el marco jurídico de referencia es el general y las políticas han de ser transversales.

Sobre la base de una política de integración que debe tender a la coordinación pero no a la armonización (como sí ocurre, por ejemplo, en el caso del asilo con la creación del $\mathrm{SECA}^{8}$ ), distintos Estados de la Unión llevan algunos años, con un especial aceleración en los últimos cinco, aplicando los denominados contratos o cursos de integración que inciden en la idea contractual de derechos y deberes, pero hacen descansar básicamente sobre el inmigrante el peso de la integración. Con diferentes puntos de coincidencia pero también con importantes divergencias se han puesto en marcha contratos o cursos de integración, o exámenes de civismo y ciudadanía (vinculantes o no), en Suecia, Dinamarca, Finlandia, Países Bajos, Austria, Bélgica, Francia, Reino Unido, Estonia (en este caso no para los nuevos inmigrantes sino básicamente dirigidos a la minoría rusa), Alemania y Suiza (Carrera 2006 y 2008; y Guiraudon, 2008) ${ }^{9}$. En nuestro caso, la LO 2/2009 no exige ningún tipo de contrato adicional de integración para los inmigrantes.

\footnotetext{
${ }^{8}$ A diferencia de lo que ocurre con la política de inmigración en la que se estipula la necesidad de colaboración, la creación del denominado Sistema Europeo Común de Asilo (SECA) exige de los Estados una armonización de sus legislación en vistas a la configuración de un sistema compartido (Vid. Gil-Bazo, 2007, Arenas 2008 y Solanes 2010 b).

9 Resulta interesante contrastar las diferentes exigencias de los Estados de la 27-UE para confirmar la ya
} 
España se distancia así de la tendencia de algunos países que han impulsado desde sus respectivas normativas nacionales programas de integración de carácter jurídicamente vinculante, retrocediendo en buena medida en lo que a reconocimiento de la diversidad se refiere (Martiniello, 2007). Ello no significa que se haya superado el debate sobre un déficit de integración coincidiendo con una crisis asumida y la idea del declive de la capacidad inclusiva del Estado del Bienestar, más bien al contrario éste continua en auge (Bommes 2003).

El concepto de integración que se vincula al contrato es, en mi opinión, muy reducido y en nada recuerda a la bidireccionalidad de la que se habla desde la Unión Europea en la medida en que la sociedad de acogida permanece impermeable a él ${ }^{10}$. También aquellos extranjeros, incluso nacionales de terceros Estados, que fuera del ámbito de aplicación personal de las legislaciones de extranjería no se ven afectados por estos contratos (como los trabajadores altamente cualificados o aquellos que se beneficien de regímenes jurídicos especiales) son ajenos a estas medidas de integración.

Ciertamente los destinatarios principales de los programas de integración vinculantes son los recién llegados, mayores de edad, que tienen un conocimiento muy primario de la lengua del país de recepción; y en segundo lugar, aquellos que deseen acceder a la residencia permanente, pero no todos los extranjeros. El vínculo que aquí se observa es el relativo a la integración y la pobreza, puesto que, el nivel económico y la dependencia se incluyen entre los factores que mayor peso adquieren a la hora de concretar si el inmigrante es o no sujeto de los programas de integración (Carrera 2006, 67). En contrapartida, el desempleo (con él los ínfimos ingresos económicos) y la dependencia de los recursos del Estado del Bienestar pueden interpretarse como una falta de integración por parte del inmigrante.

En el caso de Alemania, Francia y los Países Bajos, los programas de integración pretenden establecer un estándar compartido con la finalidad de asegurar las mismas medidas para todos los inmigrantes legales y permanentes en todo el país. Para ello es imprescindible articular un procedimiento administrativo común, que es siempre el punto de partida, de tal forma que solo existe una posible adaptación a las necesidades individuales y particularidades locales en una segunda fase. En este esquema, se supone que un programa de integración eficiente es aquel que ha de proporcionar, inicialmente, estandarización y ocuparse solo de forma colateral de la diferenciación (Michalowski 2007, 83 y Cebolla y Requena 20I0).

anunciada necesidad de coordinación sin armonización en la política de extranjería e inmigración, dicha comparación puede encontrarse, entre otros, en la Dirección General de Políticas Interiores de la Unión, Departamento de Política Derechos de los Ciudadanos y Asuntos Constitucionales, Estudio comparativo de la legislación en materia de inmigración legal en los 27 Estados miembros de la Unión Europea. Incluye una evaluación de las condiciones y formalidades impuestas por cada Estado miembro para los recién llegados, PE 393.28I, Bruselas, febrero 2008. Cfr. IVIE/ Compromiso social Bancaja (20II).

Io Desde que en el año 2000 la COM 757, COM 757 final, de 22 de noviembre, Comunicación de la Comisión al Consejo y al Parlamento Europeo sobre una política comunitaria de inmigración, estableciera que la integración es «un proceso bidireccional basado en derechos mutuos y obligaciones correspondientes a los ciudadanos de terceros países en situación legal y de la sociedad de acogida, que permite la plena participación de los inmigrantes», dicho concepto no ha dejado de consolidarse en instrumentos como, por ejemplo, la COM (2005) 389 sobre el Programa Común para la Integración que recogía los Principios Comunes Básicos sobre Integración, aprobados por el Consejo de Ministros de Justicia y Asuntos de Interior de la Unión Europea el ig de noviembre de 2004; el Pacto Europeo sobre Inmigración y Asilo, refrendado en el Consejo Europeo de I6 de octubre de 2008; el Dictamen del Comité Económico y Social Europeo sobre Elementos para la estructura, organización $y$ funcionamiento de una plataforma para la mayor participación de la sociedad civil en la promoción a nivel comunitario de políticas de integración de nacionales de terceros países, Diario Oficial C 27/95 de 3 de febrero de 2009; la UE (20I0), Declaración de Zaragoza: Conferencia Ministerial Europea sobre integración, MTIN/Zaragoza I5-I6 de abril (que insiste en adoptar un enfoque global y transversal para la integración, destacando la necesidad de crear una nueva agenda sobre integración, que incluya un mecanismo de coordinación como el propuesto en el Programa de Estocolmo); o la ya mencionada COM (20II) 29I final. 
En estos supuestos, el éxito del contrato de integración es más que cuestionable al menos por dos razones: por una parte, en determinados casos, como el francés, se puede valorar desde una perspectiva meramente cuantitativa que evidencia el número total de exámenes que se han superado respecto a los contratos efectivamente arbitrados, pero eso no aporta un dato sobre lo que realmente está ocurriendo en cuanto a la integración en la vida diaria del inmigrante; por otra parte, la superación incluso con éxito de exámenes de idioma y cultura no garantiza otras dimensiones que también van unidas a la integración. Aunque el contrato se dé por superado éste, por sí mismo, no asegura la efectiva implementación en el mercado laboral o la interrelación con la población autóctona ${ }^{\mathrm{II}}$.

En realidad es obligado plantearnos si estos instrumentos persiguen impulsar la integración de la población inmigrante, o si responden a un contexto marcado por las políticas de inmigración restrictivas en las que los elementos en buena medida también simbólicos (de preservación de la identidad nacional, de los valores constitucionales, etc.) adquieren una especial relevancia y la figura del inmigrante queda estigmatizada (De Lucas 2008 b).

Los contratos incluidos en los programas de integración no se articulan exclusivamente en base a una carencia de la misma en el ámbito social, sino que se relacionan de forma muy estrecha con la crisis general de los sistemas sociales o lo que se ha considerado como el del declive de la capacidad inclusiva del Estado del Bienestar también en los países europeos. Los contratos de integración como obligación jurídica han sido considerados, desde determinados sectores, como un retorno a la asimilación, puesto que inciden especialmente en la adquisición de competencias lingüísticas y de carácter cívico. Este esfuerzo añadido que se requiere al inmigrante no va aparejado de una mayor inserción o promoción en atención a sus circunstancias específicas en el mercado laboral. Parece más oportuna la potenciación de una integración socioeconómica en lugar de la asimilación cultural clásica que es la idea fundamental por la que se articulan estos contratos (Brubaker 2003), sin perder de vista la igualdad jurídica.

En este contexto, es acertada la opción española perfilada con la LO 2/2009, concretada en el mencionado artículo 2 ter que conecta la integración con las acciones formativas, el conocimiento y respeto de los valores constitucionales y estatutarios de España, de los valores de la Unión Europea, los derechos humanos, las libertades públicas, la democracia, la tolerancia y la igualdad entre mujeres y hombres, la incorporación al sistema educativo, el aprendizaje del conjunto de lenguas oficiales, y el acceso al empleo.

Siendo estos ejes los básicos de la política estatal de inmigración han de articularse atendiendo a la imperativa cooperación y coordinación, también por las Comunidades Autónomas. No puede perderse de vista la progresiva asunción de competencias que están llamadas a experimentar dichas Comunidades en materia de inmigración en los próximos años, tal como señalábamos anteriormente.

Precisamente dentro de ese nuevo contexto competencial Comunidades como la Valenciana o Cataluña, por citar solo dos ejemplos, han aprobados sus respectivas leyes en relación a la integración y acogida de inmigrantes para desarrollar las competencias

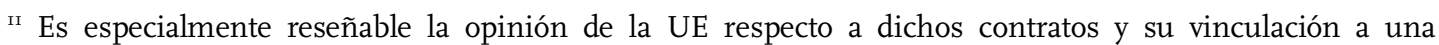
integración eficaz, así en la COM (20II) 29I final, p. 8, se mantiene: «La formalización de los derechos y obligaciones de los inmigrantes recién llegados mediante un «contrato de admisión y de integración» continuó en algunos Estados miembros. En muchos Estados miembros se ha prestado especial atención a la necesidad de aprender el idioma de la sociedad de acogida y al aumento de las tasas de desempleo de los inmigrantes, adoptando medidas para mejorar su acceso al empleo. En la mayor parte de los Estados miembros continuó la tendencia a desarrollar estrategias integrales y sistemas de supervisión para el seguimiento de sus resultados. Es preciso realizar esfuerzos adicionales para mejorar la eficacia de la integración. La UE tiene que reconocer y apoyar la contribución de los inmigrantes al crecimiento económico, garantizando al mismo tiempo la cohesión social...Para la Comisión, un enfoque 'ascendente' basado en una gobernanza bien organizada a nivel local y regional es la mejor manera de alcanzar este objetivo». 
legalmente atribuidas sin sobrepasar los límites de la norma estatal ${ }^{12}$. Así la LODYLE insiste en que la Administración General del Estado, las Comunidades Autónomas y los Ayuntamientos colaborarán en sus acciones en este ámbito tomando como referencia sus respectivos planes de integración. Esa coordinación partirá del Plan Estratégico de Inmigración, tras el cual el Gobierno y las Comunidades Autónomas acordarán en la Conferencia Sectorial de Inmigración programas de acción bienales para reforzar la integración social de los inmigrantes. Los programas se financiarán con cargo tanto a un fondo estatal como a través de la cofinanciación por parte de las Administraciones receptoras de las partidas del fondo.

En este contexto las Comunidades Autónomas han adquirido una especial relevancia en la acreditación documental de la integración del inmigrante. Así en el RD 557/20II se establece la posibilidad de presentar cuatro tipos de informes, que son competencia de las Comunidades Autónomas, aunque en dos de ellos (arraigo y vivienda adecuada) pueden establecer éstas que sean emitidos por las Entidades Locales. Dichos informes son el de esfuerzo de integración, de arraigo, sobre vivienda adecuada y el de escolarización de menores.

El primero de dichos informes, el de esfuerzo de integración, será emitido por la Comunidad Autónoma del lugar de residencia del extranjero, a petición suya, en caso de renovación de la autorización de residencia temporal no lucrativa, renovación de la autorización de residencia temporal por reagrupación familiar y renovación de la autorización de residencia temporal y trabajo por cuenta propia o ajena. Dicho informe no tiene que presentarse obligatoriamente, pero puede ser alegado por el extranjero en caso de no acreditar el cumplimiento de alguno de los requisitos normativamente previstos para la renovación de la autorización y será tenido en cuenta como información a valorar por la oficina de extranjería. Dentro de su contenido mínimo el informe tendrá la certificación, en su caso, de la participación activa del extranjero en acciones formativas destinadas al conocimiento y respeto de los valores constitucionales de España, los valores estatutarios de la Comunidad Autónoma en que se resida, los valores de la Unión Europea, los derechos humanos, las libertades públicas, la democracia, la tolerancia y la igualdad entre mujeres y hombres, así como el aprendizaje de las lenguas oficiales del lugar de residencia. En este sentido, la certificación hará expresa mención al tiempo de formación dedicado a los ámbitos señalados. El informe tendrá en consideración las acciones formativas desarrolladas por entidades privadas debidamente acreditadas o por entidades públicas.

La valoración positiva del esfuerzo de integración del extranjero acreditado mediante el informe positivo de la Comunidad Autónoma de su lugar de residencia en los mencionados trámites administrativos, ha de entenderse como un añadido a la posibilidad de renovación de la autorización en cuestión cuando el extranjero lo presente o cuando éste no cumpla los requisitos exigidos a tal efecto, pero no como un requisito de carácter excluyente.

En la misma línea ha de interpretarse el informe exigido en el caso del arraigo social ${ }^{13}$. En dicho caso, normativamente se exige tener vínculos familiares con otros extranjeros residentes o, en su defecto, presentar un informe de arraigo que acredite la integración social. Es decir, si se tienen vínculos familiares con otros extranjeros residentes, referidos a los cónyuges o parejas de hecho registradas, ascendientes y descendientes en

${ }^{12}$ Cfr. Ley I5/2008, de 5 de diciembre, de la Generalitat, de Integración de las Personas Inmigrantes en la Comunidad Valenciana, BOE núm. 9, de Io de enero de 2009; Decreto 93/2009, de ro de julio, por el que se aprueba el Reglamento de la Ley 15/2008, de 5 de diciembre, de la Generalitat, de Integración de las Personas Inmigrantes, DOCV núm. 6056, de I4 de julio; y Ley Io/20Io, de 7 de mayo, de acogida de las personas inmigradas y de las regresadas a Cataluña BOE núm. I39, de 8 de junio de 2010.

I3 Vid. Instrucción DGI/SGRJ/3/20II sobre aplicación del reglamento de la Ley Orgánica 4/2000, sobre derechos y libertades de los extranjeros en España y su integración social, en materia de informe de arraigo, de 28 de junio de 201 . 
primer grado y en línea directa, no será necesario solicitar el informe. Ambos documentos son necesarios únicamente, cuando en el informe se exima al extranjero de la necesidad de contar con un contrato de trabajo siempre y cuando acredite que cuenta con medios de vida suficientes. Este informe es emitido por la Comunidad Autónoma en la que tenga su domicilio habitual o por el Ayuntamiento de su lugar de residencia en caso de que así lo haya establecido la Comunidad Autónoma.

El carácter de estos informes, en definitiva, no permite conectar las previsiones de la legislación española con las exigencias de un contrato de integración de carácter vinculante exclusivo para los inmigrantes.

En efecto, la no consideración de obligaciones jurídicas específicas vinculadas a la integración para los inmigrantes, parece estar en consonancia con las diferentes acciones autonómicas y estatales puestas en marcha hasta la fecha para favorecer la integración. Me refiero a los planes de integración de las Comunidades Autónomas que comparten áreas de acción como acogida, educación, salud, trabajo, formación, alojamiento, servicios sociales, sensibilización, cooperación al desarrollo y asistencia jurídica (Covas et al. 2003); y planteamientos básicos. Entre los primeros, Martínez de Lizarrondo (2009, 58-6I) destaca la pretensión de atender a la población sin enfatizar los criterios de permanencia legal, la identificación de las políticas de integración con políticas multidimensionales, la aplicación del principio de normalización y universalidad como criterio rector de todas las políticas sociales, evitando la creación de recursos específicos que puedan suponer la instauración de una red paralela, aunque no se rechace la posibilidad de articular servicios especializados para facilitar el acceso a los servicios normalizados para toda la población.

Los planes autonómicos de integración no obvian que, como señalábamos anteriormente, el mercado de trabajo y el modelo de bienestar son elementos determinantes de la integración de los inmigrantes en el contexto español. En el contexto de las diferentes Comunidades Autónomas tradicionalmente se ha producido una estratificación de la inmigración basada sobre todo en características socio-estructurales de los espacios de acogida (Laparra y Martínez de Lizarrondo 2003). Es decir, las diferencias en la estructura económica y demográfica, la situación del mercado de trabajo y la configuración de las políticas sociales, además de la propia ubicación geográfica, dan lugar a distintas situaciones aun cuando muchos elementos proceden de la legislación básica estatal.

A nivel estatal el Plan Estratégico de Ciudadanía e Integración 2007-2010 (PECI I), se dirigió al conjunto de la población sin exigir especiales obligaciones a la población inmigrante. Más bien al contrario los tres principios en los que se basaba dicho plan (igualdad, ciudadanía e interculturalidad) pretendían establecer un marco político que orientara las actuaciones del conjunto de la sociedad en ese proceso bidireccional, de adaptación mutua, que la integración debería ser. La integración en el Plan era concebida, como un proceso continuo, dinámico y resultado de distintas fases y aspectos, a corto, medio y largo plazo (Solanes 20I0 c, 90). Otras premisas especialmente reseñables venían a completar esta concepción inicial de la integración, entre ellas: la convicción de que el proceso de integración y su gestión debía de compartirse entre las distintas administraciones y también los actores sociales; la consideración del PECI como un marco de colaboración que podía permitir dinamizar políticas; la necesidad de un enfoque global; el hecho de articular las distintas medidas para el conjunto de la ciudadanía; y la consideración transversal de las cuestiones relativas a la integración de la población inmigrada en el marco de todas las políticas públicas relevantes (Cachón 2008, 223-224).

Con el PECI I se intentaba, por primera vez, articular un modelo que cohesionara la intervención autonómica, de tal forma que el Estado se implicara en las políticas de integración. Una de las características a destacar era que la financiación que el Estado aportaba se completaba en parte por las respectivas Comunidades Autónomas, pero eran 
éstas las que decidían en qué políticas concretas invertirían esos recursos económicos atendiendo a sus necesidades específicas (Martínez de Lizarrondo 20I0, 33-34).

El Plan Estratégico de Ciudadanía e Integración 20II-20I4 (aprobado el 23 de septiembre de 20II) tiene como principal objetivo fortalecer la cohesión social, ahora bien en un nuevo contexto migratorio caracterizado por la reducción de flujos de entrada de inmigrantes. Uno de sus objetivos es reforzar tanto los instrumentos y políticas de integración como los servicios públicos y de participación, para garantizar el acceso de todos los ciudadanos en condiciones de igualdad. No se contemplan, por tanto medidas específicas para los inmigrantes, sino que se reconoce que su integración es uno de los retos más importantes que afronta la sociedad española y un pilar básico de la política integral de inmigración puesta en marcha desde 2004, junto con los consabidos principios de la lucha contra la inmigración irregular, la vinculación de la inmigración legal a las necesidades del mercado de trabajo y la cooperación al desarrollo de los países de origen.

El PECI II mantiene la bidireccionalidad del proceso de integración, insistiendo en la necesidad de adaptación mutua, y diseñando una política basada en acciones que se dirigen a todos los ciudadanos, tanto inmigrantes como autóctonos. En mi opinión, esa transversalidad no es compatible con un integración contractual y vinculante, sino que es la vía de esa finalidad de normalización de la convivencia en una sociedad diversa. Por eso el Plan recoge nuevas medidas necesarias para dar respuesta a los retos del futuro inmediato como son la gestión de la diversidad, el fortalecimiento del capital humano y la igualdad de oportunidades para garantizar la cohesión social.

\section{Un viraje en forma de selección y recorte}

Los sistemáticos recortes en las formas de entrada y permanencia en el ámbito de la regularidad que se han producido en la legislación española, se ubican en un contexto europeo marcado por una política restrictiva fuertemente condicionada por una implícita lógica de «estado de sitio» (De Lucas 2009 b), que en realidad no puede suponer una inmigración cero. En efecto, como se desprende del Estudio Prospectivo Anual sobre Crecimiento de 20 Io (MEMO/II/II, 3) en la Unión Europea la demanda de mano de obra ha continuado creciendo y a pesar de las altas tasas de desempleo, siguen existiendo empleadores que no encuentran a las personas adecuadas para cubrir sus vacantes. Para mantener la recuperación económica y preservar las sistemas de bienestar, la Unión Europea ya se ha dado cuenta de que necesita resolver la disparidad que existe entre la oferta de cualificaciones y la demanda del mercado laboral. Así se concreta en la Estrategia Europa 2020, al establecer las directrices para el empleo, en la que se emplaza a los Estados a alcanzar una tasa de empleo del $75 \%$ en 2020 , y una mayor adecuación entre las cualificaciones adquiridas a través de la educación y la formación y las necesidades del mercado de trabajo. Para afrontar este reto es necesario incidir en la empleabilidad de la población activa nacional, aumentar la tasa de empleo de las mujeres y de los trabajadores de más edad, continuar con la preferencia comunitaria, pero también es imprescindible aprovechar el potencial procedente de la inmigración y de los nacionales de terceros Estados que ya son residentes en la Unión (COM (2OII) 29I final, 3) ${ }^{\mathrm{I} 4}$.

Las últimas propuestas lanzadas desde la Unión Europea en pro de un enfoque global de la migración que se concrete en el desarrollo de un política común, se decanta por entrar en la competencia mundial por la captación de élites profesionales, en detrimento de la mano de obra catalogada como primaria. Ciertamente en el ámbito internacional, esta competencia no es reciente para países como Estados Unidos, Canadá, Australia o Nueva

${ }^{14}$ COM (20II) 29I final Comunicación de la Comisión al Parlamente Europeo y al Consejo, de 24 de mayo de 20II, Informe anual sobre Inmigración y Asilo (2010). 
Zelanda, incluso en la dimensión europea Gran Bretaña o Alemania hace tiempo que decidieron adoptar incentivos para atraer a los trabajadores altamente cualificados. La diferencia, ahora, radica en que se presenta como una ofensiva comunitaria pensada para resultar tan, o más, atractiva que la de sus potenciales adversarios. Ello no supone la total renuncia a los esquemas de selección hasta ahora vigentes, entre otras cuestiones porque cada uno de los Estados sigue teniendo la competencia para regular la entrada y permanencia de nacionales de terceros países en su territorio siempre que atienda a las directrices, en forma de mínimos, de la Unión.

Así, tras décadas apostando por un modelo de inmigración catalogada como no cualificada (lo que no significa que realmente lo fuera) pensada para ocupar puestos de trabajo en los últimos peldaños de la escalera laboral, con una voluntad utilitarista de no permanencia reflejada en el clásico modelo del trabajador huésped (Castles 2006), el conjunto de los Estados de la Unión han formulado una segunda variable de diferenciación.

El instrumento por excelencia adoptado por la Unión para hacer viable esta opción es la Directiva del Consejo relativa a las condiciones de entrada y residencia de nacionales de terceros países para fines de empleo altamente cualificado ${ }^{\text {I5 }}$ que ha sido traspuesta al ordenamiento jurídico español por la LO 2/2009.

Uno de los primeros problemas de gran impacto que plantean medidas de este tipo es el de evitar la fuga de cerebros en los países en vías de desarrollo, puesto que como ha destacado, entre otras, la Organización Internacional del Trabajo ${ }^{16}$ existe una vinculación entre iniciativas de este tipo y la fuga de talentos.

El informe sobre Desarrollo Humano de $2009^{\text {I7 }}$, a propósito de la competencia por el talento a escala mundial, señala que países como Estados Unidos han podido atraer a las élites gracias a la calidad de sus universidades y a la infraestructura de investigación, junto con sus favorables normas sobre patentes. Los países con medidas de ingreso más flexibles y mejores oportunidades a largo plazo han logrado atraer mano de obra cualificada, en cambio lo contrario ocurre en aquellos Estados que restringen la duración de la estancia. Los programas para atraer trabajadores cualificados pueden incluir un sistema de puntos vinculado con exámenes del mercado laboral o exigencias de los empleadores Ciertamente, resulta complicado implementar un sistema centralizado de planificación de recursos humanos, ante cambios estructurales y crisis económicas. El sistema de puntos tiene la ventaja de la simplicidad, por eso han sido utilizados por los gobiernos de los Estados de destino para premiar a trabajadores inmigrantes altamente cualificados o atraer a trabajadores con especializaciones necesarias y escasas en el mercado laboral del país en concreto. Parece evidente que los verdaderos motivos que subyacen a estas políticas se conectan con sectores con divergencias entre los beneficios y costos de la formación de los

\footnotetext{
is Directiva 2009/50/CE del Consejo de 25 de mayo de 2009, Diario Oficial de la Unión Europa de I8 de junio de 2009 . Conviene tomar en consideración que esta directiva fue el resultado de trabajos previos encaminados a coordinar la actuación de los Estados en la estimulación de la migración cualificada, así por ejemplo, es reseñable el Dictamen del Comité de las Regiones «Un enfoque global de la migración: el desarrollo de una política europea de inmigración laboral y su encaje en las relaciones con los países terceros» 2008/C 257/04, DOUE de 9 de septiembre de 2008, que se inserta en la iniciativa de Lisboa. Dicho Comité sugiere que se tenga en cuenta el nivel educativo del inmigrante, su experiencia laboral, su capacitación lingüística y otros factores que se consideren relevantes. Asimismo se pide a la Comisión que, previo análisis y evaluación de las posibilidades de contratación de dichos trabajadores, tenga en cuenta los compromisos del Consejo sobre la aproximación de los procedimientos de admisión por razones vinculadas al empleo, tal como prevé el Plan de política en materia de migración legal (cfr. Dictamen del Comité de Regiones sobre el «Plan de política en material de inmigración legal- Lucha contra la inmigración illegal-Futuro de la red europea de migración» CDR 233/2006, DOUE de I3 de febrero de 2007).

i6 Documento temático para la sesión 3: Migración por motivos laborales, dentro de las fronteras e internacionalmente. Foro OIT 2007.

${ }^{17}$ PNUD, Informe sobre Desarrollo Humano 2009 « Superando barreras: movilidad $y$ desarrollo humanos ».
} 
profesionales, como por ejemplo, la sanidad (PNUD 2009, 94 у I23).

En efecto, como recuerda, entre otros, Wihtol de Wenden $(2006,263)$ impedir la fuga de cerebros y animarles a que vuelvan a su país de origen son ideas discutibles. En principio, los propios Estados generadores de inmigrantes, tienen en las remesas de éstos (cualificados o no) unas cantidades nada desdeñables. Además si las élites cualificadas no tienen posibilidades reales de ejercer sus talentos en sus respectivos países, por ejemplo por el tipo de régimen imperante, hay que aceptar que el retorno solo se hará de forma limitada. La idea de inmigración circular no parece por tanto casar con la atracción de trabajadores altamente cualificados.

La estrategia de intentar atraer a las élites hacia Europa se completa, con la ofensiva demoledora a la inmigración que no cumple ese requisito de la alta cualificación, así, por ejemplo, dos instrumentos han sido pensados para «afrontar» esos flujos migratorios que no se desean: la Directiva relativa a normas y procedimientos comunes en los Estados miembros para el retorno de los nacionales de terceros países en situación irregular $^{18}$ y el mencionado Pacto Europeo sobre Inmigración y Asilo.

Por lo que se refiere al Pacto Europeo sobre Inmigración y Asilor9 es un documento político que viene a refundir la política europea común de inmigración. Con este documento los Estados miembros de la Unión Europea se comprometen a orientar las políticas migratorias en torno a cinco compromisos: organizar la inmigración legal teniendo en cuenta las prioridades, las necesidades y la capacidad de acogida determinada por cada Estado miembro y favorecer la integración; luchar contra la inmigración irregular, especialmente garantizando el retorno de los extranjeros en situación de irregularidad al país de origen o a un país de tránsito; reforzar la eficacia de los controles fronterizos; construir la Europa del asilo; establecer una cooperación global con los países de origen y de tránsito favoreciendo las sinergias entre las migraciones y el desarrollo. Las medidas para hacer efectivos estos compromisos serán tanto nacionales como europeas (Carrera y Guild 2008; Trujillo y Ortega 20I0).

Dentro del primer compromiso mencionado, el Pacto señala que la política de inmigración legal deber ser elegida y concertada. Es decir, la inmigración legal debe reflejar una doble voluntad: la del emigrante y la del país de acogida. El beneficio debe ser mutuo. Por tanto, cada Estado miembro puede poner en práctica políticas de inmigración profesional y decidir el número de personas que desea admitir en su territorio en función de las necesidades de su mercado de trabajo. En concreto, apuesta por reforzar el atractivo de la Unión Europea para trabajadores altamente cualificados. Al mismo tiempo, entiende que es necesario facilitar las migraciones temporales y circulares, evitando la fuga de cerebros de los países de origen de los migrantes.

\footnotetext{
${ }^{18}$ Conocida como «directiva de la vergüenza» por la flagrantes vulneraciones de derechos que conlleva, Directiva 2008/II5/CE del Parlamento Europeo y del Consejo de I6 de diciembre de 2008, Diario Oficial de la Unión Europea de 24 de diciembre de 2008 , que ha sido traspuesta al ordenamiento jurídico español por la LO 2/2009. Es además especialmente relevante prestar atención a la transposición nacional de esta Directiva, para asegurar que se respetan los principios básicos de derechos humanos desarrollados en el contexto del Consejo de Europa y en la jurisprudencia del Tribunal Europeo de Derechos Humanos.

I9 Pacto Europeo de Inmigración y Asilo, Consejo de la Unión Europea, I3440/08, Bruselas 24 de septiembre de 2008; refrendado por el Consejo Europeo de los días I5 y i 6 de octubre de 20Io. Su seguimiento se ha dado a través de diferentes instrumentos: COM (2009) 266 final, Comunicación de la Comisión al Consejo y al Parlamento Europeo, de io de junio de 2009, Método de seguimiento para supervisar la aplicación del Pacto Europeo sobre Inmigración y Asilo; COM (2010) 2I4 final Informe de la Comisión al Parlamento Europeo y al Consejo, de 6 de mayo de 20I0, Primer informe anual sobre Inmigración y Asilo (2009); y la ya mencionada COM (20II) 29i final Comunicación de la Comisión al Parlamente Europeo y al Consejo, de 24 de mayo de 20II, Informe anual sobre Inmigración y Asilo (2010).
} 
Estas políticas, tanto en su dimensión de mano de obra no cualificada como en la de captación de trabajadores altamente cualificados, parecen propugnar una vuelta al más puro liberalismo económico, en una forma de entender los flujos migratorios más propia de una concepción liberal de la economía incipiente a principios del siglo XX, que apostaba por la no regulación de las migraciones internacionales en pro de la acción que a tal efecto surtiría el mercado de trabajo (Cfr. Fanjul 20Io).

En segundo lugar, como señalábamos, la mencionada Directiva del Consejo relativa a las condiciones de entrada y residencia de nacionales de terceros países para fines de empleo altamente cualificado, es el punto de referencia de la política europea de atracción de talentos. Dicho instrumento es conocido como la directiva de la tarjeta azul por el tipo de documento que ofrece a los inmigrantes. Esta denominación se concretó por referencia a la green card que en EEUU permite la estancia y el trabajo a los extranjeros en dicho Estado, aunque su alcance es mucho más limitado que el estadounidense. Una de las diferencias más importantes es que la green card supone un permiso de estancia permanente mientras que la tarjeta azul europea se ofrece por cinco años, aunque pasados éstos el inmigrante puede solicitar el estatuto de residente de larga duración.

La principal virtud de la Directiva de la tarjeta azul es que establece reglas comunes en todos los Estados miembros para facilitar la entrada y residencia de inmigrantes de alta cualificación y de sus familias y hacer posible su traslado a otro país de la Unión tras un tiempo de estancia y trabajo en el primero que les recibió. Para que el trabajador inmigrante puede entrar legalmente necesita recibir una oferta de trabajo de al menos un año de duración para ocupar un puesto para el que se requiere alta cualificación y por el que se tiene que pagar un salario equivalente al menos a I,5 veces el salario medio bruto del país receptor. Esto no significa, sin embargo, que exista la posibilidad de moverse a otro Estado miembro de forma automática, en tal caso el inmigrante debe pasar por un proceso de comprobación semejante al inicial.

Esta tarjeta ha sido pensada como un elemento clave para paliar el déficit actual europeo en innovación (significativo respecto a EEUU y Japón y al que se están incorporando otras economías como China e India), sin embargo, para avanzar en esa competencia por talentos, la Unión Europea adolece de dos grandes desafíos, por una parte la diversidad idiomática, y por otra, las políticas proteccionistas nacionales de sus respectivos mercados de trabajo (González y Sorroza 2009, Io y I3).

La Directiva de la tarjeta azul de la Unión Europea está pensada, como veíamos para articular un vía rápida y flexible que permita satisfacer la demanda europea de trabajadores que puedan considerarse como altamente cualificados, con tratamiento diferencial y más beneficioso respecto de quienes no lo son. Las previsiones de dicha Directiva apuntan un sistema sectorial y selectivo para una determinada categoría de trabajadores nacionales de terceros países. Como apuntan Carrera y Pinyol (2010, 55), la compatibilidad de esta Directiva con el principio de no-discriminación que recoge el artículo 2i de la Carta de los Derechos Fundamentales de la Unión Europea ${ }^{2 \circ}$ es discutible, ya que sólo se ofrece una vía administrativa más fácil para la admisión, residencia y reagrupación familiar, así como un estatus legal más seguro, a aquellos nacionales de terceros Estados «considerados rentables y/o altamente cualificados». La Directiva deja un significativo margen de discreción a los Estados para definir y especificar las condiciones y los privilegios que se derivan de la mencionada tarjeta azul de la Unión Europea, de ahí precisamente que se cuestione ese hipotético valor de marco normativo común que parece que debía justificar su existencia (Guild, 2007).

El impulso que la Unión Europea quiere dar al desarrollo de un marco jurídico

${ }^{20}$ Carta de los Derechos Fundamentales de la Unión Europea, OJ C303/I, I4 de diciembre de 2007. Adquiere carácter vinculante tras la entrada en vigor del Tratado de Lisboa. 
común para la inmigración legal, se completa con el proyecto de Directiva de permiso único que tras ser objetada en octubre de 20I0, fue apoyada por el Parlamento Europeo por 3II votos a favor, $2 \mathrm{I} 6$ en contra y $8 \mathrm{I}$ abstenciones, teniendo que ser sometida ahora a los Ministros de Justicia y Asuntos de Interior de la Unión Europea para que analicen las enmiendas aprobadas por el Parlamento. Este proyecto, pretende reducir los trámites administrativos y simplificar el procedimiento de admisión de los nacionales de terceros países que quieren vivir o trabajar en un Estado miembro. Esta norma permitiría a los trabajadores y a los empresarios solicitar los permisos de residencia y trabajo mediante un procedimiento único. En cualquier caso, el proyecto nace con la objeción de Reino Unido, Irlanda y Dinamarca, que se niegan a aplicar estas disposiciones.

Con la misma finalidad de consolidación de un marco legal común se trabaja en la propuesta de Directiva del Parlamento Europeo y del Consejo relativa a las condiciones de entrada y residencia de nacionales de terceros países en el marco de un traslado dentro de una misma empresa ${ }^{2 \mathrm{I}}$.

De momento, de este acervo pensado para la consolidación de un mismo estatuto jurídico, el instrumento ya aprobado y cuya implementación está pendiente es el de la tarjeta azul. El proceso de transposición de la Directiva de la tarjeta azul de la Unión Europea debía completarse en junio de 20II. Sin embargo, a estas alturas sólo unos pocos Estados han comunicado a la Comisión sus medidas de transposición. Entre ellos se incluye España que la ha incorporado a su ordenamiento a través de la LO 2/2009.

El artículo 38 ter de la LODYLE regula la residencia y trabajo de los profesionales altamente cualificados. Estos trabajadores obtendrán una autorización de residencia y trabajo documentada con una tarjeta azul de la UE. Además el artículo 40.2 b) LODYLE recoge la exención de la situación nacional de empleo de los profesionales altamente cualificados, incluyendo técnicos y científicos contratados por entidades públicas, universidades o centros de investigación, desarrollo e innovación dependientes de empresas, sin perjuicio de la aplicación del régimen específico de autorización aplicable de conformidad con la Ley.

En cuanto a investigadores y científicos, cabe destacar que el artículo 25 bis de la LODYLE crea un nuevo tipo de visado, denominado «visado de investigación» y el artículo 38 bis de la misma determina el «Régimen especial de los investigadores». La norma prevé la concesión de autorizaciones de residencia y trabajo a los extranjeros que desarrollen este tipo de actividades. Asimismo, finalizado el convenio de acogida, tanto el investigador como sus familiares reagrupados, podrán ser autorizados para residir y ejercer una actividad lucrativa sin necesidad de nuevo visado.

Por otra parte en esta línea de fomento de una inmigración selectiva, en España en 2007 se creó la denominada Unidad de Grandes Empresas y Colectivos Estratégicos (o Unidad de Gestión de Extranjería-Colectivos Estratégicos (UGE-CE)), a la que específicamente se refiere actualmente el RD 577/20II. La teórica finalidad de esta Unidad es dar una repuesta ágil a las necesidades planteadas por las empresas y organismos que requieren traer a España personal no comunitario altamente cualificado, al tiempo que ofrecer un asesoramiento experto sobre las posibilidades legislativas existentes y sus procedimientos.

El título IX del RD 557/20II incorpora, por primera vez, las autorizaciones de residencia y trabajo en cuya actividad profesional concurran razones de interés económico,

\footnotetext{
${ }^{2 \pi}$ Vid. Dictamen del Comité Económico y Social Europeo sobre la «Propuesta de Directiva del Parlamento Europeo y del Consejo relativa a las condiciones de entrada y residencia de nacionales de terceros países en el marco de un traslado dentro de una misma empresa», [COM(20I0) 378 final - 20I0/0209 (COD)] (20II/C 2I8/I9), DOUE de 23 de julio de 20 II.
} 
social o laboral, o relativas a la realización de trabajos o desarrollo o docentes, que requieran alta cualificación, o de actividades artísticas de especial interés cultural, y que está vinculada a la denominada Unidad de Grandes Empresas, dando cabida a pequeñas y medianas empresas en razón de sectores estratégicos de la economía ${ }^{22}$.

Así reforzar la capacidad de atracción de la Unión Europea para los trabajadores altamente cualificados, y facilitar la acogida de estudiantes e investigadores se ha convertido en un eje central de la política de extranjería española. Por ejemplo, durante el año 20ıo, las iniciativas dirigidas a favorecer el acceso de trabajadores altamente cualificados han merecido una especial atención. Es significativo el hecho de que los plazos de resolución son más breves en las autorizaciones solicitadas por aquellas personas físicas o jurídicas en calidad de empleadores tal como exige la normativa, establecidas en España, a favor de estos trabajadores extranjeros que puedan catalogarse como altamente cualificados, cuando son tramitadas por medio de este procedimiento. Asimismo, la solicitud de autorización de residencia por reagrupación familiar puede presentarse de forma simultánea a la relativa al trabajador extranjero o bien con posterioridad.

El informe anual de políticas de inmigración y asilo en España $(2010,52)$ conecta la concesión de las autorizaciones destinadas a profesionales altamente cualificados, con la necesidad de proteger la suficiencia de recursos humanos en el país de origen. En este sentido se insiste en no favorecer la fuga de cerebros a la que antes aludíamos, ya que en general, la legislación española en materia de extranjería incluye cláusulas que favorecen la migración circular a través de la contratación en origen para trabajos de temporada, exigiendo el compromiso de retorno a su país y permitiendo el regreso a España en años posteriores, sin quedar sujetos a la situación nacional de empleo ni a limitaciones sectoriales o geográficas. Un compromiso de la política española es seguir fomentando estos proyectos de migración circular, que conllevan el compromiso de retornar y facilitan sucesivos procesos de contratación.

La correcta articulación de la migración circular, en cuanto política de inmigración de carácter temporal por definición, es vital también para no dificultar la integración social de los nacionales de terceros países, con independencia de su estatuto jurídico como trabajadores altamente cualificados o no. Sin duda es necesario desarrollar instrumentos legislativos concretos y coherentes que implementen el nexo de las migraciones y el desarrollo «que hasta ahora sólo existen en la retórica» (Carrera y Pinyol 20Io, 78).

\section{Reflexiones finales}

A modo de conclusión acerca de los diferentes temas abordados pueden plantearse algunas reflexiones. En primer lugar, respecto a la recomendación entorno a necesidad de potenciar una inmigración regular, o en la terminología que utilizan los diferentes instrumentos europeos «legal», es imprescindible apuntar la necesidad de una gestión global del mercado de trabajo que no pierda de vista la importancia de los flujos migratorios.

Es decir, tomando en consideración que el canal por el cual acceden los nacionales de terceros países a Europa tiene un efecto directo sobre su estatuto jurídico, en cuanto que su nivel de derechos será mayor o menor, es necesario arbitrar vías legales de entrada. Sin

\footnotetext{
${ }^{22}$ Una de las características reseñables de este tipo de procedimiento se contempla en el artículo i8o del RD 557/20II al señalar «I. El empleador que pretenda contratar a un trabajador extranjero no residente en España, en base a lo previsto en este título, deberá presentar personalmente, o a través de quien válidamente tenga atribuida la representación legal empresarial, la correspondiente solicitud de autorización ante la Dirección General de Inmigración. 2. Con la solicitud en modelo oficial deberá acompañarse la documentación exigible de acuerdo con el tipo de autorización...»
} 
duda, el mercado de trabajo seguirá siendo el principal instrumento de la migración legal, pero deberá gestionarse teniendo en cuenta las necesarias aportaciones que han venido y vendrán de la mano de la movilidad humana.

Por una parte, las políticas restrictivas que establecen estrechas medidas de entrada o permanencia en el ámbito de la legalidad, y la publicidad que de las mismas se hace, repercuten tanto en las conductas de las personas autóctonas como en las de los inmigrantes y no siempre obtienen los fines que dicen perseguir. En la situación de irregularidad los inmigrantes cambian el modo y la frecuencia de sus viajes a los países de origen, quedando más atados a los de destino, de forma que también se desorientan respecto a los cambios que en aquéllos se producen disminuyendo su proyecto de retorno. Lo que se da es una modificación del proyecto migratorio pero no una renuncia a él. El efecto real de esa especie de irregularidad a largo plazo, incluso en las peores ocasiones perpetua, es que el retorno se sustituye por la instalación e inmovilidad y la idea de traer a la familia acaba siendo el fin principal. De igual modo que la irregularidad comporta la disminución de la rotación o del movimiento de ida y vuelta, también conlleva una especie de invisibilidad (en el sentido de pretender pasar desapercibido) en la vida social que se traslada a la jurídica (Izquierdo 2006 b). Se produce así la mayor ineficacia posible de la legislación que genera y aumenta exactamente los efectos que dice querer combatir.

Por otra parte, el desarrollo a corto plazo de la política migratoria europea, y también la española, está llamado a centrarse en la inmigración altamente cualificada que relegará a un segundo plano los flujos masivos de décadas anteriores. El viraje hacía la inmigración escogida es la opción de la Unión para los próximos años. En la actualidad no hay un método que haya sido establecido a nivel europeo para evaluar la falta de mano de obra cualificada en los diferentes Estados de la Unión, ni tampoco para saber si los nacionales de terceros países tienen las competencias y cualificaciones necesarias para suplir dicha insuficiencia, en todo caso la urgente necesidad de abordar tales carencias es compartida en toda la Unión. La gestión eficaz de la inmigración y el fomento tanto de la participación efectiva cuanto de la inclusión en el empleo, son imprescindibles para alcanzar los objetivos de empleo establecidos en la Estrategia Europa 2020 (COM (2OII) 29I final, 3).

Si se quiere contrarrestar ese desfase existente entre las necesidades del mercado laboral y la oferta de cualificaciones, será necesario abrir el debate entorno al reconocimiento $u$ homologación de las titulaciones de las que disponen los nacionales de terceros países. En esta línea trabaja la Comisión para intentar articular instrumentos que permitan examinar la adecuación entre las competencias y la oferta, por ejemplo, el panorama de Cualificaciones (que se prevé para 20I2), el Observatorio Europeo de Ofertas de Empleo o el Boletín Europeo de Movilidad Profesional. Está por ver si ello supondrá una flexibilización en las estrictas políticas de homologaciones nacionales.

La concreción a nivel español de estas pautas europeas ya se está realizando con la mencionada Unidad de Grandes Empresas, en especial, la Unidad de Gestión de Extranjería-Colectivos Estratégicos pensada para potenciar esa inmigración selectiva. Ahora bien, una vez se resida en territorio nacional es fundamental garantizar un acceso al mercado de trabajo que no resulte discriminatorio. Este acceso no discriminatorio al empleo supone un gran reto en un Estado como el español donde, como veíamos, el trabajo junto a la vivienda son dos de los ámbitos donde se producen transversalmente mayores niveles de discriminación.

Por eso esta dimensión laboral como motor de la inmigración legal no puede, en ningún caso, obviar la necesidad de fomentar la cohesión social. De lo contrario, las políticas de inmigración más que propiciar la integración favorecerán un regreso a la asimilación basado en la estricta valoración de las personas según la posición del grupo con el que comparte características relevantes. Ciertamente, la focalización en la perspectiva 
exclusivamente del empleo no puede ser sensible a las desigualdades estructurales y las discriminaciones o tratos diferenciales que tienen un carácter básicamente grupal (Joppke, 2007).

De ahí, en segundo lugar, la importancia de conjugar la política de inmigración y la de integración como un todo, de tal forma que el estatuto jurídico del inmigrante facilite y potencie su integración. Ciertamente la integración ha de ser una cuestión, no sólo pero también, de derechos, de los mismos que disfruta el conjunto de la sociedad en la que el inmigrante se encuentra, exactamente en la misma medida que lo son las obligaciones jurídicamente establecidas. Eso es lo que supone un Estado de Derecho, nos situamos así en el centro del autogobierno democrático, en ese ideal de la autonomía pública basada en el principio de que quienes están sujetos a la ley también deberían ser sus autores (Benhabib 2005, I54).

La concepción unilateral de la integración en forma de deber contractual específico es, en mi opinión, difícilmente compatible con una visión global del proceso de integración, es decir, con la consideración de que ésta necesita de forma ineludible un enfoque multidimensional que supere la estricta consideración del conocimiento de la lengua o la cultura como indicadores, casi exclusivos, de la integración y que además lleva aparejada un proceso temporal que no se corresponde con los plazos contractuales. La integración en su dimensión bidireccional, que afecte también a la población autóctona, y que deconstruya los estereotipos intencionalmente vinculados a este fenómeno, es imprescindible.

Por este motivo, a priori, ha de valorarse positivamente que en el ámbito español por un lado no se haya introducido un contrato de integración exclusivo y excluyente; y por otro se estén arbitrando medidas de integración, como las que se contemplan en el PECI II, que están pensadas en una dimensión transversal y dirigidas al conjunto de los administrados.

El derecho, en este contexto, puede ser un instrumento de indudable valor en ese gran reto de futuro que es la lucha contra la exclusión social. Una vía también en el caso de la inmigración para intentar suplir lo que De Lucas (2009c, I4) ha denominado como el «déficit de las tres R», es decir, de respeto, reconocimiento y representación. Tal como el mencionado autor señala las actuaciones que siguieron a los disturbios de las banlieus en Francia, en otoño de 2005 no fueron más que la escenificación del fracaso de la política de integración francesa. De nada sirvió en el caso francés los más imaginativos programas de interculturalidad, de inmersión en usos y costumbres o las proclamas de tolerancia y solidaridad, puesto que se obvió lo fundamental, la necesidad de comenzar por la igualdad en las condiciones de trabajo, en el salario o en derechos básicos como el de la salud.

En efecto, en la adopción de políticas de integración multidimensionales conviene comenzar insistiendo en la necesidad de favorecer para las personas inmigrantes el acceso a los derechos sociales tales como la educación, la sanidad, la vivienda o los servicios sociales, así como la integración laboral y social, ciertamente porque son los aspectos más precarios en las legislaciones de los distintos Estados miembros de la Unión Europea y también en España.

Es más, el proceso de integración exige a nivel jurídico-político lo que se ha denominado una «laicización de las identidades», entendiéndola no sólo en clave religiosa sino también cultural. Es decir, la existencia de una pertenencia común en un espacio de derechos, obligaciones y valores compartidos, y una pertenencia singular, en un espacio privado en el que cultivar la diferencia. Al Estado le correspondería ocuparse de la dimensión política de la sociedad, de preservar su identidad desde esta perspectiva, en la cual se asientan los valores constitucionales, ese ha de ser el nexo común e ineludible (Naïr 2006, 207). 
En definitiva, las personas inmigrantes, como el resto de sujetos de derecho, en los actuales Estados democráticos, han de ser jurídicamente concebidas como miembros para ubicarse en las raíces cosmopolitas de la democracia (Beck 2008). De esta forma puede afirmarse que tales individuos están de acuerdo con el contrato social, es decir, que admiten en base a esa ficción común compartida la existencia de una autoridad, de unas normas y leyes, a las que se someten, y si no lo hacen entran en juego los mecanismos generales previstos por el ordenamiento a tal efecto. Solo así, en mi opinión, puede garantizarse la cohesión, la paz social, puesto que «el hombre es un ser naturalmente sociable, y el que vive fuera de la sociedad por organización y no por efecto del azar, es ciertamente, o un ser degradado, o un ser superior a la especie humana; y a él pueden aplicarse aquellas palabras de Homero (La Iliada, IX, 63): «Sin familia, sin leyes, sin hogar...» El hombre, que fuese por naturaleza tal como lo pinta el poeta, sólo respiraría guerra, porque sería incapaz de unirse con nadie como sucede a las aves de rapiña» (Aristóteles, La Política, I, I).

\section{Bibliografía}

AÑÓN, M. J. (20I0): «Integración: una cuestión de derechos», Revista Arbor 477, p. 625-38

AJA, A. (2006): «La evolución normativa sobre inmigración», en E. Aja y J. Arango (eds.), Veinte años de inmigración en España. Perspectiva jurídica y sociológica (1985-2004), Barcelona: Fundación CIDOB, p. I7-44.

ARANGO, J. (1985): «Las <leyes de las migraciones> de E. G. Ravenstein, cien años después», REIS 32, p. 7-26.

ARENAS, N. (2008): «The Southern Border of Europe: 'Right to asylum between Seas and Fences'. The Spanish Position relating to the Transposition of the Procedures Directive», en K. Zwaan (ed.), The Procedures Directive: Central Themes, Problem Issues and Implementation in Selected Member States, The Netherlands, Nijmegen: Wolf Legal Publishers, p. 75-85.

BECK, U. (2008): «Las raíces cosmopolitas de la democracia: el caso de la Unión Europea», Sistema: Revista de ciencias sociales 206 , p. 3-20.

BENHABIB, S. (2005): Los derechos de los otros, Barcelona: Gedisa.

BOMMES, M. (2003): «The shrinking inclusive capacity of the national welfare state. International migration and the deregulation of identity formation», The Multicultural Challenge. Comparative Social Research 22, p. $43-67$.

BRUBAKER, R. (2003): «The Return of Assimilation? Changing Perspectives on Immigration and its Sequels in France, Germany, and the United States», en Ch. Joppke y E. Morawska (eds.), Toward Assimilation and Citizenship. Immigrants in Liberal Nation-States, London: Palgrave Macmillan, p. 39-58.

CACHÓN, L. (2008): «La integración de y con los inmigrantes en España: debates teóricos, políticas y diversidad territorial», Política $y$ Sociedad 45 (I), p. 205-35.

- (2009): La «España inmigrante»: marco discriminatorio, mercado de trabajo y políticas de integración, Barcelona: Anthropos.

- (20II) (coord.): Inmigración y conflictos en Europa. Aprender para una mejor convivencia, Barcelona: Editorial Hacer.

CARRERA, S. (2006): «Integration of Immigrants versus Social Inclusion: A Typology of Integration Programmes in the EU», in T. Balzacq and S. Carrera (eds), Security versus Freedom: A Challenge for Europe's Future, Aldershot: Ashgate Publishing, p. 87-II4.

CARRERA, S. y GUILD, E. (2008): The French Presidency's European Pact on Immigration and Asylum: Intergovernmentalism vs. Europeanism? Security vs. Rights?, Bruselas: CEPS Policy Brief I70, Centre for European Policy Studies.

CARRERA, S. y PINYOL, G. (20I0): Autoridades locales $y$ regionales en el Espacio de Libertad, Seguridad $y$ Justicia. ¿Hacia una estrategia de multigobernanza para el Programa de Estocolmo?, Barcelona: Documentos CIDOB. Migraciones 22.

CASTLES, S. (2006): «Guestworkers in Europe: a Resurrection?», Internacional Migration Review 4 (4), p. 74I66.

CEBOllA, H. y REQUENA, M. (2010): Marroquíes en España, los Países Bajos y Francia: gestión de la diversidad e integración, Madrid: Área: Demografía, Población y Migraciones Internacionales, Real Instituto ElCano, Documento de Trabajo II. 
COVAS, C. et al (2003): Los planes de las Comunidades Autónomas para la integración social de las personas inmigrantes, Madrid: Confederación Sindical de Comisiones Obreras.

DE LUCAS, J. (2003): Globalización e Identidades. Claves políticas y jurídicas, Barcelona: Icaria. Antrazyt.

- (2006): «La integración de los inmigrantes: la integración política, condición del modelo de integración», en J. De Lucas y L. Díez, La integración de los inmigrantes, Madrid: Centro de Estudios Políticos y Constitucionales, p. II-43.

- (2008 a): «Cal y arena de la Unión Europea ante la inmigración», Página abierta I95.

- (2008 b): «Las globalizaciones y los derechos», Enrahonar, 40/4I, p. 55-66.

- (2009 a): «Reforma del marco jurídico de la inmigración: políticas que no superan el test básico», Papeles de relaciones ecosociales y cambio global, I05, p. II5-22.

- (2009 b): «La inmigración y la lógica de 'estado de sitio' (a propósito de algunas claves recientes de la política europea de inmigración)», en J. De Lucas y A. Solanes (coord.), La igualdad en los derechos: claves de la integración, Madrid: Dykinson, p. 2I-40.

- $(2009$ c) «Inmigración, diversidad cultural, reconocimiento político», Papers 94, p. II-27.

DE LUCAS, J. y SOLANES, A. (2009): La igualdad en los derechos: claves de la integración, Madrid: Dykinson.

EMN (Red Europea de Migraciones),

- (2009) Programas y estrategias referentes al retorno asistido y reintegración en terceros países. España, septiembre 2009. Disponible en: http://extranjeros.mtin.es; y en http://www.emn.europa.eu

- (2010 a) Informe anual de políticas de inmigración y asilo. España 2010. Disponible en: http://extranjeros.mtin.es; y en http://www.emn.europa.eu

- (2010 b) Satisfacción de la demanda laboral a través de la inmigración en España, diciembre 2010. Disponible en: http://extranjeros.mtin.es; y en http://www.emn.europa.eu

FANJUL, G. (20I0): «Migraciones internacionales: las consecuencias de gobernar el siglo XXI con políticas del siglo XIX», Área: Demografía, Población Y Migraciones/Cooperación y Desarrollo, ARI 56/2010, Real Instituto Elcano.

GARCÍA JUAN, L. (20I0): «La STC 3I/20IO, de 28 de junio. Punto y final en materia de competencias en inmigración», Revista Catalana de Dret Públic.

GIL-BAZO, M. T. (2007): «The Protection of Refugees under the Common European Asylum System. The Establishment of a European Jurisdiction for Asylum Purposes and Compliance with International Refugee and Human Rights Law», Cuadernos Europeos de Deusto 36, p. I53-64.

GONZÁLEZ, C. y SORROZA, A. (2009): «¿Hacia una política europea de inmigración? Un desafío para la Presidencia Española de 2009», Documentos de Trabajo Real Instituto Elcano de Estudios Internacionales $Y$ Estratégicos 57 .

GUIRAUDON, V. (2008): «Contratos de integración para inmigrantes: tendencias comunes y diferencias en la experiencia europea», Área: Demografía, Población y Migraciones Internacionales ARI 43/2008, Real Instituto ElCano.

GUILD, E. (2007): «EU Policy on Labour Migration: A First Look at the Commission's Blue Card Initiative». CEPS Policy Briefi45, Centre for European Policy Studies.

HABERMAS, J. (2000): Facticidad y Validez. Sobre el derecho y el Estado democrático de derecho en términos de teoría del discurso, Madrid: Trotta.

HUMAN RIGHTS WATCH (2008): The Netherlands: Discrimination in the Name of Integration, UNHCR Refworld número I disponible en: http://www.unhcr.org/refworld/docid/482d36732.html.

ILLAMOLA, M. (2008): Hacia una gestión integrada de las fronteras. El Código de Fronteras Schengen y el cruce de fronteras en la Unión Europea, Barcelona: Documento CIDOB Migraciones I5.

IVIE/Compromiso social Bancaja (2OII): «La población extranjera en los grandes países europeos», Capital Humano I30.

IZQUIERDO, A. (2006 a): Demografía de los extranjeros. Incidencia en el crecimiento de la población, Madrid: Fundación BBVA.

- (2006 b) «Cuatro razones para pensar en la inmigración irregular», en C. Blanco, C. (ed.). Migraciones. Nuevas Movilidades en un mundo en movimiento, Barcelona: Anthropos, p.I39-59.

- (2008): «Una reflexión sobre la integración de los inmigrantes extranjeros en España: de la bonanza a la crisis», Estudios mirandeses: Anuario de la Fundación Cultural «Profesor Cantera Burgos» 28 (2), p. 22I-42. 
JOPPKE, Ch. (2007): «Transformation of immigrant integration in Western Europe: civic integration and antidiscrimination policies in the Netherlands, France, and Germany», Word Politics 59 (2), p. 243-73.

LA SPINA, E. (20II): Familias transnacionales, sociedades multiculturales e integración: España, Italia y Portugal en perspectiva comparada, Madrid: Dykinson.

LAPARRA, M. y MARTINEZ DE LIZARRONDO, A. (2003): «Espacio local, escenario para la integración social», en M. Laparra (ed), Extranjeros en el purgatorio. Integración social de los inmigrantes en el espacio local, Barcelona: Bellaterra, p. 32I-50.

MARTINEZ DE LIZARRONDO, A.

- (2009): «Una mirada a los planes de integración de las comunidades autónomas», Inmigración y políticas sociales, en L. Cachón y M. Laparra (eds), Barcelona: Edicions Bellaterra, p. 5I-70.

- (20I0): «La incidencia del Fondo de Apoyo y el PECI en las políticas autonómicas de integración de inmigrantes», Revista del Ministerio de Trabajo e Inmigración 85, p. 3I-45.

MARTINIELLO, M. (2007): Cómo combinar la integración y la diversidad: el desafío de una ciudadanía multicultural en la UE, Gipuzkoa: Ikuspegi. Observatorio Vasco de Inmigración Informes 3.

MEZZADRA, S. (2005): Derecho de fuga. Migraciones, ciudadanía y globalización, Madrid: Traficantes de sueños.

MICHALOWSKI, I. (2007) «Modelos de acogida en Alemania, Francia y los Países Bajos: diseño y efectividad de los programas de acogida e integración», en J. Biles; I. Michalowski y L. Winnemore, Políticas y modelos de acogida. Una mirada transatlántica: Canadá, Alemania, Francia y los Países Bajos, Serie Migraciones I2, Barcelona: Fundació CIDOB, p. 67-92.

NAÏR, S. (2006): Y vendrán...Las migraciones en tiempos hostiles, Barcelona: Bronce- Planeta.

PAJARES, M. (2010): Inmigración y mercado de trabajo. Informe 2010, Madrid: Ministerio de Trabajo e Inmigración.

PUMARES, P.; GRACIA, A. y ASENSIO, Á. (2006): La movilidad laboral y geográfica de la población extranjera en España, Madrid: Ministerio de Trabajo y Asuntos Sociales y Observatorio Permanente de la Inmigración.

ROJO TORRECILLA, E. (2OIO): «La situación actual del retorno voluntario en el marco de las nuevas políticas de inmigración y de los cambios acaecidos entre la población extranjera en el mercado de trabajo español», Ponencia, Sevilla, 28 de octubre.

SANTOLAYA, P. (2009): «La gestión de la inmigración en la VIII legislatura (2004-2008)», Revista del Ministerio de Trabajo e Inmigración 80, p. 8I-96.

SOLANES, A. (2005): «La política de inmigración en la Unión Europea desde tres claves», Arbor 7I3, p. 8I-IO०.

- (2010 a): «Inmigración y responsabilidad municipal», Documentación Social I58, p. I9I-Io.

- (2010 b): «Un decálogo sobre la crisis del asilo en España», Sistema 218, p. I03-22.

- (20I0 c): «Un balance tras 25 años de leyes de extranjería en España: I985-2010», Revista del Ministerio de Trabajo e Inmigración 90, p. 77-IO2.

TRUJILLO, A. J. y OTEGA, J. M. (coord.) (2010): Inmigración y asilo: problemas actuales y reflexiones al hilo de la nueva Ley reguladora del derecho de asilo $y$ de la protección subsidiaria $y$ de la entrada en vigor del Tratado de Lisboa, Madrid: Ediciones Sequitur.

WIHTOL DE WENDEN, C. (2006): «Algunas reflexiones sobre la ley francesa de inmigración e integración de 24 de julio de 2006», Revista Española del Tercer Sector 4, p. 26I-66. 